\title{
Analysis of the Water Adsorption Isotherms in UiO-based Metal-Organic Frameworks
}

Mason C. Lawrence ${ }^{\dagger}$ and Michael J. Katz ${ }^{* \dagger}$

${ }^{\dagger}$ Department of Chemistry, Memorial University of Newfoundland, St. John's Newfoundland, A1B $3 X 7$

*mkatz@mun.ca

\section{Table of Contents}

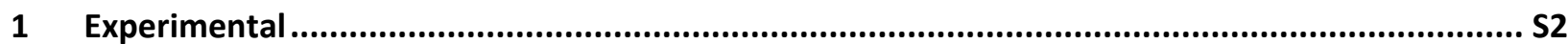

1.12 '-amino-1, $1^{\prime}: 4,1^{\prime \prime}$-terphenyl-4,4"-dicarboxylic acid $\left(\mathrm{NH}_{2}-\mathrm{H}_{2} \mathrm{TPDC}\right)$....................................... 2

1.1.1 Synthesis of diethyl-2'-amino-1,1:4,1' '-terphenyl-4,4' '-dicarboxylate (Et- $\mathrm{NH}_{2}$-TPDC)...... S2

1.1.2 Synthesis of 2'-amino-1,1':4,1"-terphenyl-4,4"-dicarboxylic acid $\left(\mathrm{NH}_{2}-\mathrm{H}_{2} \mathrm{TPDC}\right)$.............. S2

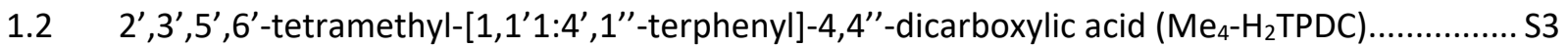

1.2.1 Synthesis of diethyl-2',3',5',6'-tetramethyl-[1,1'1:4',1''-terphenyl]-4,4''-dicarbolate ........ S3

1.2.2 Synthesis of 2',3',5',6'-tetramethyl-[1,1'1:4',1''-terphenyl]-4,4''-dicarboxylic acid (Me $4^{-}$

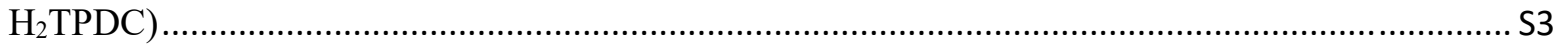

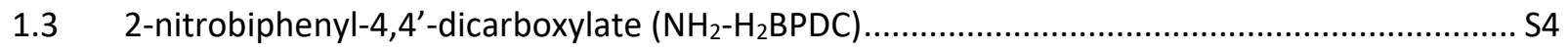

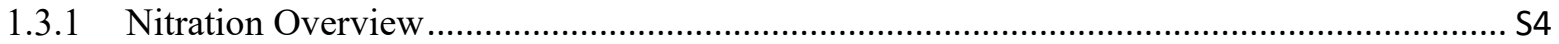

1.3.2 Synthesis of 2-nitro-dimethyl-biphenyl-4,4'-dicarboxylate …............................................. S4

1.3.3 Synthesis of 2-amino-dimethyl-biphenyl-4,4'-dicarboxylate.............................................. S4

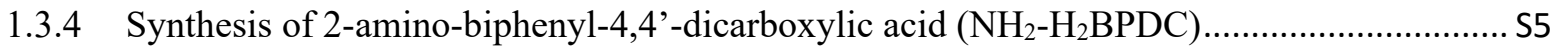

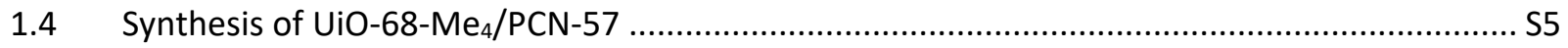

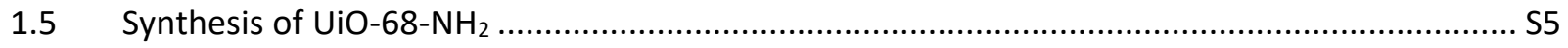

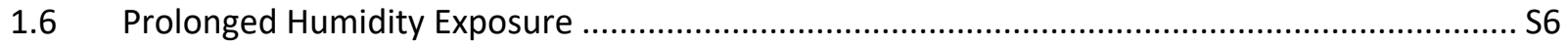

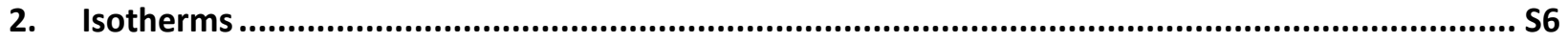

2.1 Pore Size Distribution Fits from Nitrogen Gas Adsorption Isotherms ................................... S6

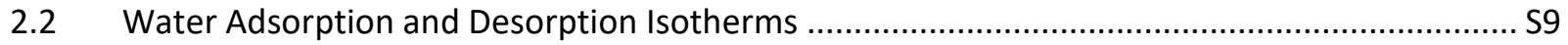

2.3 Pore Size Distributions from Nitrogen Gas and Water Vapour Adsorption Isotherms. ........... S10

$2.4 \quad$ Water Adsorbed per Zirconium Centre ….......................................................................... S11

2.5 Isosteric Heats of Adsorption of Water on UiO-66 .............................................................. S11

2.6 Comparison of water isotherms for UiO-68 synthetic procedures........................................ S11

2.7 Water adsorption/desorption swing isotherms. ................................................................. S13

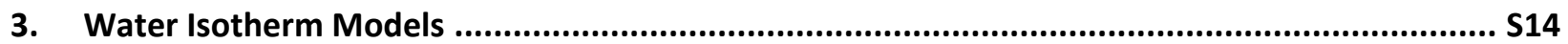

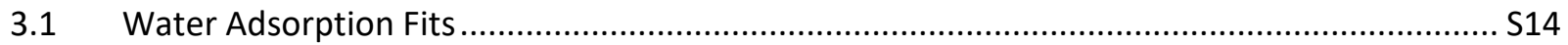

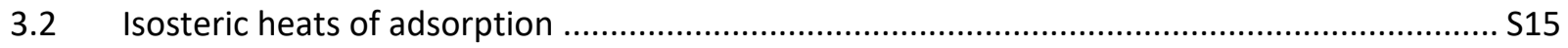

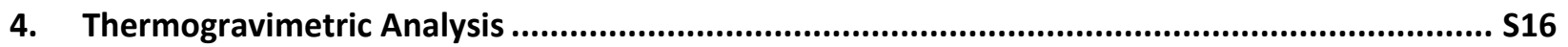

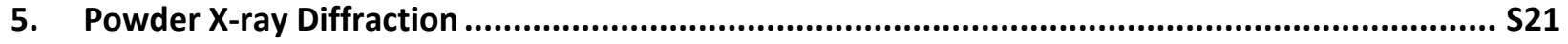

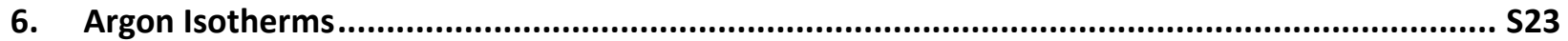

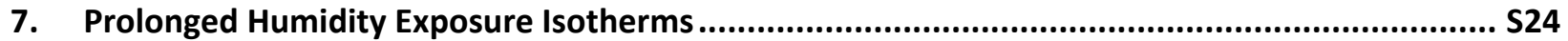

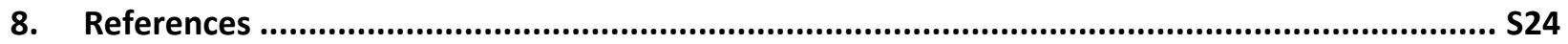




\section{Analysis of the Water Adsorption Isotherms in UiO-based Metal-Organic Frameworks}

Mason C. Lawrence and Michael J. Katz

\section{Experimental}

1.12 '-amino-1,1':4,1"'-terphenyl-4,4"'-dicarboxylic acid $\left(\mathrm{NH}_{2}-\mathrm{H}_{2} \mathrm{TPDC}\right)$

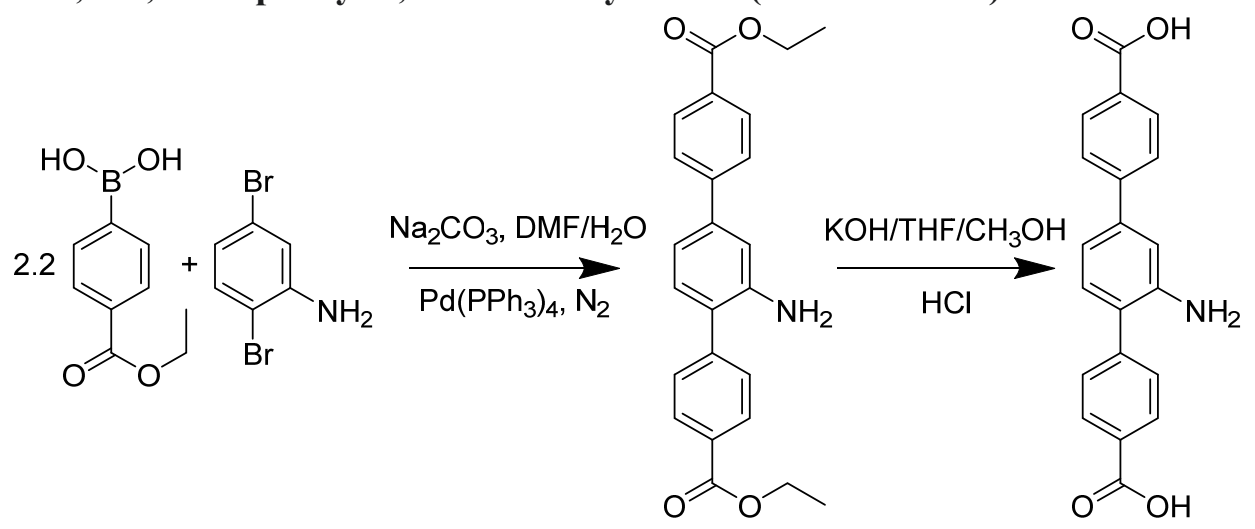

1.1.1 Synthesis of diethyl-2'-amino-1,1:4,1''-terphenyl-4,4',-dicarboxylate (Et-NH $\mathrm{NH}_{2}$-TPD)

Similar to literature methods, ${ }^{1} 25 \mathrm{~mL}$ of dimethylformamide (DMF) and $21 \mathrm{~mL}$ of deionized water were combined in a 3-neck $500 \mathrm{~mL}$ round bottom flask and sparged under nitrogen while stirring. After 30 minutes $1.0 \mathrm{~g}$ (4 mmoles) of 2,5-dibromoanaline, $2.2 \mathrm{~g}$ (11 mmoles) of 4-(ethoxycarbonyl)phenylboronic acid, $1.4 \mathrm{~g}$ (17 mmoles) of sodium bicarbonate, and $40 \mathrm{mg}(0.035$ mmoles, 0.9 mole \%) of tetrakis(triphenylphosphine)palladium $(0)$ was added to the flask. The contents were heated at $90{ }^{\circ} \mathrm{C}$ for 16 hours under a flow of nitrogen. Subsequently, the reaction was cooled to room temperature and the grey precipitate was isolated by suction filtration. The precipitate was dissolved in ethyl acetate and washed with water to remove any salts from the organic component. The organic layer was dried over magnesium sulfate and the solvent was removed under heat and reduced pressure to yield a brown solid of Et- $\mathrm{NH}_{2}$-TPDC. The ${ }^{1} \mathrm{H}-\mathrm{NMR}$ was collected on a Bruker $500 \mathrm{MHz}$ Avance spectrometer. The data was consistent with literature values. ${ }^{1}$ This reaction gave a $52 \%$ yield. ${ }^{1} \mathrm{H}$ NMR $(500 \mathrm{MHz}$, Chloroform- $d$ ): $\delta 8.10(\mathrm{~d}, J=8.2,2 \mathrm{H}), 8.07(\mathrm{~d}, J=8.2,2 \mathrm{H}), 7.63(\mathrm{~d}, J=8.2,2 \mathrm{H}), 7.55(\mathrm{~d}, J=8.2,2 \mathrm{H})$, $7.19(\mathrm{~d}, J=7.8 \mathrm{~Hz}, 1 \mathrm{H}), 7.06(\mathrm{dd}, J=7.8,1.8 \mathrm{~Hz}, 1 \mathrm{H}), 6.98(\mathrm{~d}, J=1.8 \mathrm{~Hz}, 1 \mathrm{H}), 4.37$ (q, $J=7.2,2 \mathrm{H})$, $4.36(\mathrm{q}, J=7.2,2 \mathrm{H}), 1.38(\mathrm{t}, J=7.2,3 \mathrm{H}), 1.37(\mathrm{t}, J=7.2,3 \mathrm{H})$.

\subsubsection{Synthesis of $2^{\prime}$-amino-1,1':4,1'-terphenyl-4,4"'-dicarboxylic acid $\left(\mathrm{NH}_{2}-\mathrm{H}_{2} \mathrm{TPDC}\right)$}

To deprotect Et- $\mathrm{NH}_{2}-\mathrm{TPDC}$, the brown solid was added to a $250 \mathrm{~mL}$ round bottom flask containing $65 \mathrm{~mL}$ of tetrahydrofuran (THF). The flask was heated at $65^{\circ} \mathrm{C}$. Once the temperature was reached, $32 \mathrm{~mL}$ of $5.5 \mathrm{~mol} / \mathrm{L}$ potassium hydroxide in methanol was added and allowed to reflux overnight. The reaction was then removed from heat and cooled to room temperature. The precipitate was isolated by suction filtration, and subsequently suspended in $65 \mathrm{~mL}$ of THF. $3.3 \mathrm{~mL}$ of trifluoracetic acid was added to the suspension and the suspension was stirred for 2 hours. The yellow product was isolated by suction filtration and washed with deionized water $(3 \times 100 \mathrm{~mL})$ followed by methanol $(3 \times 20 \mathrm{~mL})$. The ${ }^{1} \mathrm{H}-\mathrm{NMR}$ was collected on a Bruker $300 \mathrm{MHz}$ Avance III spectrometer. The spectra for $\mathrm{NH}_{2}-\mathrm{H}_{2} \mathrm{TPDC}$ was consistent with the literature. ${ }^{2}$ This reaction was quantitative. ${ }^{1} \mathrm{H}$ NMR (300 MHz, DMSO- $d_{6}$ ): $\delta 8.02(\mathrm{~d}, J=8.2 \mathrm{~Hz}, 4 \mathrm{H}), 7.74(\mathrm{~d}, J=8.2 \mathrm{~Hz}, 2 \mathrm{H}), 7.61(\mathrm{~d}, J=8.2 \mathrm{~Hz}, 2 \mathrm{H}), 7.17(\mathrm{~d}, J=7.9 \mathrm{~Hz}, 1 \mathrm{H})$, $7.16(\mathrm{~d}, J=1.8 \mathrm{~Hz}, 1 \mathrm{H}), 7.02(\mathrm{dd}, J=7.9,1.8 \mathrm{~Hz}, 1 \mathrm{H}) .{ }^{1}$ 


\section{Analysis of the Water Adsorption Isotherms in UiO-based Metal-Organic Frameworks}

Mason C. Lawrence and Michael J. Katz

1.2 2',3',5',6'-tetramethyl-[1,1'1:4',1''-terphenyl]-4,4''-dicarboxylic acid (Me $\left.{ }_{4}-\mathrm{H}_{2} \mathrm{TPDC}^{\prime}\right)$

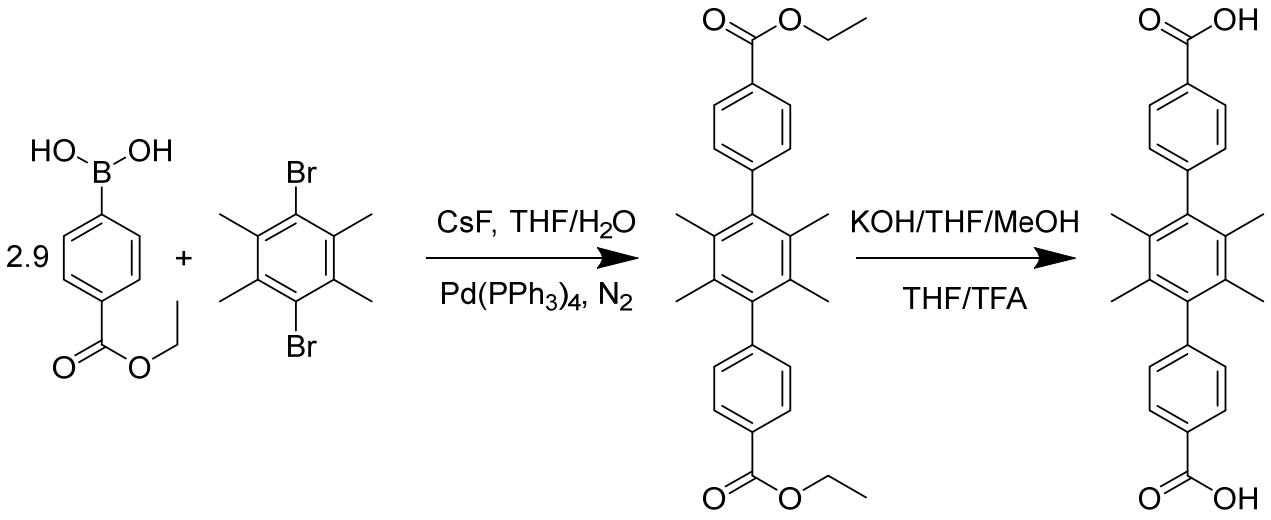

\subsubsection{Synthesis of diethyl-2',3',5',6'-tetramethyl-[1,1'1:4',1''-terphenyl]-4,4''-dicarbolate}

In a slightly modified method from the literature, ${ }^{3} 5 \mathrm{~mL}$ of DMF and $5 \mathrm{~mL}$ of deionized water were combined in a $20 \mathrm{~mL}$ Biotage microwave vial and sparged with nitrogen gas for 30 minutes. After sparging, $0.1050 \mathrm{~g}$ (0.3596 mmole) of 3,6-dibromdurene, $0.2050 \mathrm{~g}$ (1.057 mmole) of 4-(ethoxycarbonyl)phenylboronic acid, $1.15 \mathrm{~g}(1.554 \mathrm{mmol})$ of cesium fluoride and $0.0200 \mathrm{~g}(0.01731 \mathrm{mmol}$, $1.6 \mathrm{~mol} \%$ ) of tetrakis(triphenylphosphine)palladium( 0 ) was added to the vial and sparged with nitrogen for 5 minutes. The vial was placed in a Biotage Initiator microwave reactor for 35 minutes at a temperature of $140{ }^{\circ} \mathrm{C}$. The reaction was subsequently cooled to room temperature and the precipitate was isolated by suction filtration. The filtrate was washed with deionized water $(2 \times 25 \mathrm{~mL})$ followed by washing with acetone $(3 \times 15 \mathrm{~mL})$ resulting in a grey precipitate. This reaction had a $75 \%$ yield. The ${ }^{1} \mathrm{H}-\mathrm{NMR}$ was collected on a Bruker $500 \mathrm{MHz}$ Avance spectrometer. The data was consistent with literature values. ${ }^{1}{ }^{1} \mathrm{H}$ NMR $(500 \mathrm{MHz}$, Chloroform- $d): \delta 8.12(\mathrm{~d}, J=8.6 \mathrm{~Hz}, 4 \mathrm{H}), 7.26(\mathrm{~d}, J=8.6 \mathrm{~Hz}, 4 \mathrm{H})$, $4.41(\mathrm{q}, J=7.1 \mathrm{~Hz}, 4 \mathrm{H}), 1.91(\mathrm{~s}, 12 \mathrm{H}), 1.42$ (t, $J=7.1 \mathrm{~Hz}, 6 \mathrm{H})$. Note: $\mathrm{CDCl}_{3}$ overlaps with the doublet at $7.26 \mathrm{ppm}$, the integration of half the doublet was utilized to determine the relative integration.

\subsubsection{Synthesis of 2',3',5',6'-tetramethyl-[1,1'1:4',1''-terphenyl]-4,4''-dicarboxylic acid (Me - $^{\prime}$ $\mathrm{H}_{2}$ TPDC)}

In order to deprotect the carboxylic acid from 1.2.1, the product of the Suzuki-coupling from 1.2.1 was dissolved in $40 \mathrm{~mL}$ of tetrahydrofuran/methanol mixture (50:50) and $20 \mathrm{~mL}$ of $1 \mathrm{~mol} / \mathrm{L}$ potassium hydroxide in water was added and allowed to reflux overnight. The mixture was then removed from heat and allowed to cool to room temperature. The organic solvents were removed under reduced pressure and heat. The remaining solution was acidified with $1 \mathrm{~mol} / \mathrm{L}$ hydrochloric acid until a $\mathrm{pH}$ of 1 was reached. At this point, a white powder was observed. The precipitate was isolated by suction filtration and washed with deionized water $(3 \times 25 \mathrm{~mL})$ and methanol $(3 \times 10 \mathrm{~mL})$. The ${ }^{1} \mathrm{H}-\mathrm{NMR}$ was collected on a Bruker $300 \mathrm{MHz}$ Avance III spectrometer. The data was consistent with literature values. ${ }^{1}$ This reaction was quantitative. ${ }^{1} \mathrm{H}$ NMR $\left(300 \mathrm{MHz}, \mathrm{DMSO}-d_{6}\right): \delta 8.04(\mathrm{~d}, J=8.3 \mathrm{~Hz}, 4 \mathrm{H}), 7.29(\mathrm{~d}, J=$ $8.3 \mathrm{~Hz}, 4 \mathrm{H}), 1.87(\mathrm{~s}, 12 \mathrm{H})$. 


\section{Analysis of the Water Adsorption Isotherms in UiO-based Metal-Organic Frameworks}

Mason C. Lawrence and Michael J. Katz

\subsection{2-nitrobiphenyl-4,4'-dicarboxylate $\left(\mathrm{NH}_{2}-\mathrm{H}_{2} \mathrm{BPDC}\right)$}
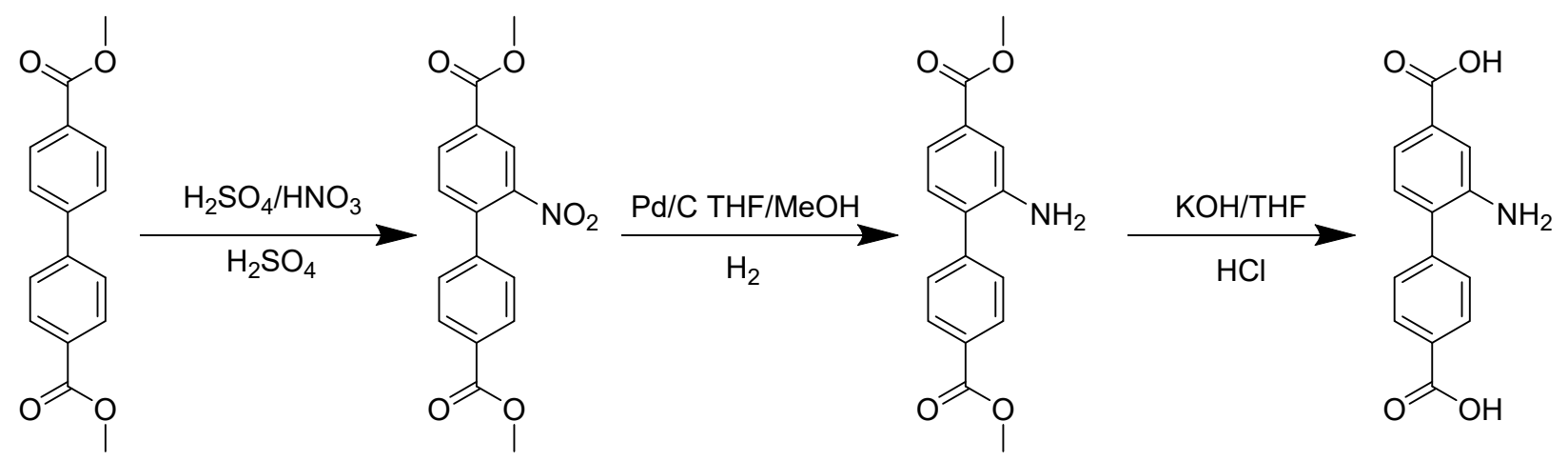

$\mathrm{NH}_{2}-\mathrm{H}_{2} \mathrm{BPDC}$

\subsubsection{Nitration Overview}

The first step in the production of $\mathrm{NH}_{2}-\mathrm{H}_{2} \mathrm{BPDC}$, is the nitration of dimethyl biphenyl-4,4'-dicarboxylate. Traditionally, the literature preparations for this step are done on relatively large scales (ca. $20 \mathrm{~g}){ }^{4}$ In our hands, scaling down the reaction without further modifications lead to a mixture of the mono-, di-, and un-substituted complexes. The main modification for this reaction is to use a more dilute $\mathrm{HNO}_{3}$ solution, to prevent localized high concentrations of $\mathrm{HNO}_{3}$, and to pre-cool the $\mathrm{HNO}_{3}$ solution.

\subsubsection{Synthesis of 2-nitro-dimethyl-biphenyl-4,4'-dicarboxylate}

In a $25 \mathrm{~mL}$ round bottom flask, $0.500 \mathrm{~g}$ ( $1.850 \mathrm{mmoles})$ of dimethyl biphenyl-4,4'-dicarboxylate was dissolved in $5 \mathrm{~mL}$ concentrated $\mathrm{H}_{2} \mathrm{SO}_{4} .12 \mathrm{~mL}$ of a concentrated solution of $\mathrm{H}_{2} \mathrm{SO}_{4}$ with $0.125 \mathrm{~mL}$ of $\mathrm{HNO}_{3}$ was chilled in an ice bath for 15 minutes. The diluted $\mathrm{HNO}_{3} / \mathrm{H}_{2} \mathrm{SO}_{4}$ solution was added dropwise to the $25 \mathrm{~mL}$ round bottom flask with stirring. The temperature was maintained below $5{ }^{\circ} \mathrm{C}$. The solution was stirred for 30 minutes and subsequently poured into a $600 \mathrm{~mL}$ beaker full of ice producing a white precipitate. The solution was stirred for 45 minutes before the precipitate was isolated by suction filtration, washed with $500 \mathrm{~mL}$ of deionized water, and allowed to dry overnight. This reaction had a $92 \%$ yield. The ${ }^{1} \mathrm{H}-\mathrm{NMR}$ was collected on a Bruker $300 \mathrm{MHz}$ Avance III spectrometer. ${ }^{1} \mathrm{H} \mathrm{NMR}(300 \mathrm{MHz}$, Chloroform- $d$ ): $\delta 8.56(\mathrm{~d}, J=1.7 \mathrm{~Hz}, 1 \mathrm{H}), 8.30(\mathrm{dd}, J=8.0,1.7 \mathrm{~Hz}, 1 \mathrm{H}), 8.12(\mathrm{~d}, J=8.6 \mathrm{~Hz}, 2 \mathrm{H}), 7.54$ $(\mathrm{d}, J=8.0 \mathrm{~Hz}, 1 \mathrm{H}), 7.41(\mathrm{~d}, J=8.6 \mathrm{~Hz}, 2 \mathrm{H}), 4.00(\mathrm{~s}, 3 \mathrm{H}), 3.95(\mathrm{~s}, 3 \mathrm{H})$.

\subsubsection{Synthesis of 2-amino-dimethyl-biphenyl-4,4'-dicarboxylate}

$0.6600 \mathrm{~g}$ (2.093 mmole) of 2-nitro-dimethyl-biphenyl-4,4'-dicarboxylate was dissolved in a 50:50 mixture of tetrahydrofuran and methanol. $70 \mathrm{mg}(0.06578 \mathrm{mmoles})$ of $10 \%$ palladium on carbon was added. The flask was capped with a rubber septum and a balloon of hydrogen (aprox. $4 \mathrm{~L}$ ) was used to sparge the solution. An additional balloon of hydrogen (aprox. $4 \mathrm{~L}$ ) was used to maintain a positive pressure of hydrogen over the reaction. The reaction was stirred overnight (ca. 20 hours) at room temperature. The next morning, the solution was filtered through celite and washed with $20 \mathrm{~mL}$ of tetrahydrofuran and $20 \mathrm{~mL}$ of methanol. The solvent was removed under reduced pressure resulting in a brown solid. No further purification was performed. This reaction was quantitative. The ${ }^{1} \mathrm{H}-\mathrm{NMR}$ was collected on a Bruker $300 \mathrm{MHz}$ Avance III spectrometer. ${ }^{1} \mathrm{H}$ NMR $(300 \mathrm{MHz}$, Chloroform- $d$ ): $\delta 8.13(\mathrm{~d}, J=8.3 \mathrm{~Hz}$, 2H), 7.55 (d, $J=8.3 \mathrm{~Hz}, 2 \mathrm{H}), 7.49$ (dd, $J=7.9 \mathrm{~Hz}, 1.6 \mathrm{~Hz}, 1 \mathrm{H}), 7.45$ (d, $J=1.6 \mathrm{~Hz}, 1 \mathrm{Hf}), 7.18$ (d, $J=$ $7.9 \mathrm{~Hz}, 1 \mathrm{H}), 3.95(\mathrm{~s}, 3 \mathrm{H}), 3.92(\mathrm{~s}, 3 \mathrm{H})$. 


\section{Analysis of the Water Adsorption Isotherms in UiO-based Metal-Organic Frameworks}

Mason C. Lawrence and Michael J. Katz

\subsubsection{Synthesis of 2-amino-biphenyl-4,4'-dicarboxylic acid $\left(\mathrm{NH}_{2}-\mathrm{H}_{2} \mathrm{BPDC}\right)$}

$0.5000 \mathrm{~g}(1.753 \mathrm{mmol})$ of 2-amino-dimethyl-biphenyl-4,4'-dicarboxylate was dissolved in $50 \mathrm{~mL}$ of tetrahydrofuran and $50 \mathrm{~mL}$ of $1 \mathrm{~mol} / \mathrm{L}$ aqueous potassium hydroxide solution. The resulting solution was heated to $40{ }^{\circ} \mathrm{C}$ and stirred overnight. Subsequently, the organic solution was removed under heat and reduced pressure. The aqueous solution was acidified with $1 \mathrm{~mol} / \mathrm{L}$ hydrochloric acid until a $\mathrm{pH}$ of 1 was reached. The resultant off white precipitate was isolated by suction filtration and washed with $150 \mathrm{~mL}$ of deionized water $(3 \times 50 \mathrm{~mL})$. This reaction was quantitative. The ${ }^{1} \mathrm{H}-\mathrm{NMR}$ was collected on a Bruker $300 \mathrm{MHz}$ Avance III spectrometer. ${ }^{1} \mathrm{H}$ NMR (300 MHz, DMSO- $\left.d_{6}\right): \delta 8.00(\mathrm{~d}, J=8.3 \mathrm{~Hz}$, 2H), $7.57(\mathrm{~d}, J=8.3 \mathrm{~Hz}, 2 \mathrm{H}), 7.42(\mathrm{~d}, 1.7 \mathrm{~Hz}, 1 \mathrm{H}), 7.22(\mathrm{dd}, J=7.8 \mathrm{~Hz}, 1.7 \mathrm{~Hz}, 1 \mathrm{H}), 7.12(\mathrm{~d}, J=$ $7.8 \mathrm{~Hz}, 1 \mathrm{H}) .^{5}$

\subsection{Synthesis of UiO-68-Me $/ \mathrm{PCN}-57$}

Method A (Main text): Following the synthesis by Goswami et al. ${ }^{6}$ In a $50 \mathrm{~mL}$ Pyrex jar, $120 \mathrm{mg}$ $(0.293 \mathrm{mmol})$ of $\mathrm{ZrOCl}_{2} \bullet 8 \mathrm{H}_{2} \mathrm{O}, 100 \mathrm{mg}(0.267 \mathrm{mmoles})$ of $\mathrm{Me}_{4}-\mathrm{H}_{2} \mathrm{TPDC}, 20 \mathrm{~mL}$ of DMF, and $1 \mathrm{~g}$ of benzoic acid ( $1 \mathrm{~g} 8.19 \mathrm{mmol})$ were combined and sonicated for 3 minutes. The resulting solution was placed in the oven at $100{ }^{\circ} \mathrm{C}$ overnight. Once removed from the oven and cooled to room temperature the mixture was transferred to a $50 \mathrm{~mL}$ centrifuge tube and centrifuged for 5 minutes at $7800 \mathrm{RPM}$. The solution was decanted, and $(25 \mathrm{~mL})$ fresh DMF was added, shaken, centrifuged, and the solution was decanted. This process was repeated a total of 3 times. This process was then repeated 3 times with $25 \mathrm{~mL}$ methanol. The resulting precipitate was placed in a vacuum oven at $80^{\circ} \mathrm{C}$ overnight.

Method B (Si discussion only): In a $50 \mathrm{~mL}$ Pyrex Jar, $46 \mathrm{mg}(0.1974 \mathrm{mmoles})$ of $\mathrm{ZrCl}_{4}, 64 \mathrm{mg}$ (0.1709 mmoles) of $\mathrm{Me}_{4}-\mathrm{H}_{2} \mathrm{TPDC}, 40 \mathrm{~mL}$ of DMF, and $1 \mathrm{~mL}$ of trifluoroacetic acid were combined and sonicated for 3 minutes. The resulting solution was placed in the oven at $120{ }^{\circ} \mathrm{C}$ for 4 days. Once removed from the oven and cooled to room temperature the mixture was transferred to a $50 \mathrm{~mL}$ centrifuge tube and centrifuged for 5 minutes at 7800 RPM. The solution was decanted, and $(25 \mathrm{~mL})$ fresh DMF was added, shaken, centrifuged, and the solution was decanted. This process was repeated a total of 3 times. This process was then repeated 3 times with $25 \mathrm{~mL}$ methanol. The resulting precipitate was placed in a vacuum oven at $80{ }^{\circ} \mathrm{C}$ overnight.

\subsection{Synthesis of UiO-68- $\mathrm{NH}_{2}$}

Method A (Main text): In a slightly modified procedure outlined by Schaate et al. ${ }^{7} 120 \mathrm{mg}$ $(0.515 \mathrm{mmol})$ of $\mathrm{ZrCl}_{4}, 1.88 \mathrm{~g}$ of benzoic acid $(15.4 \mathrm{mmol})$ and $20 \mathrm{~mL}$ of DMF were combined in a $50 \mathrm{~mL}$ Pyrex jar and sonicated for 3 minutes. After sonication a clear colorless solution resulted, $170 \mathrm{mg}(0.510 \mathrm{mmol})$ of $\mathrm{NH}_{2}-\mathrm{H}_{2}$ TPDC and $0.028 \mathrm{~mL}$ of deionized water were added and sonicated again for 3 minutes to form a cloudy yellow solution. This was placed in a $120^{\circ} \mathrm{C}$ oven overnight. Once removed from the oven and cooled to room temperature to a $50 \mathrm{~mL}$ centrifuge tube and centrifuged for 5 minutes at 7800 RPM. The solution was decanted, and $(25 \mathrm{~mL})$ fresh DMF was added, shaken, centrifuged, and the solution was decanted. This process was repeated a total of 3 times. This process was then repeated 3 times with $25 \mathrm{~mL}$ methanol. The resulting precipitate was placed in a vacuum oven at $80{ }^{\circ} \mathrm{C}$ overnight.

Method B (SI discussion only): In a $50 \mathrm{~mL}$ Pyrex jar $130 \mathrm{mg}$ of L-proline (1.13 mmol), $54 \mathrm{mg}$ of $\mathrm{ZrCl}_{4}$ $(0.23 \mathrm{mmol}), 73 \mathrm{mg}$ of $\mathrm{NH}_{2}-\mathrm{H}_{2}$ TPDC $(0.22 \mathrm{mmol})$ and $10 \mathrm{~mL}$ of DMF were combined and sonicated for 5 minutes and a cloudy yellow solution formed. 20 microL of concentrated $\mathrm{HCl}$ was added and sonicated again for 2 minutes. This was then placed in a $120^{\circ} \mathrm{C}$ oven overnight. Once removed from the oven and cooled to room temperature to a $50 \mathrm{~mL}$ centrifuge tube and centrifuged for 5 minutes at 7800 RPM. The solution was decanted, and $(25 \mathrm{~mL})$ fresh DMF was added, shaken, centrifuged, and 


\section{Analysis of the Water Adsorption Isotherms in UiO-based Metal-Organic Frameworks}

Mason C. Lawrence and Michael J. Katz

the solution was decanted. This process was repeated a total of 3 times. This process was then repeated 3 times with $25 \mathrm{~mL}$ acetone. The resulting precipitate was placed in a vacuum oven at $80{ }^{\circ} \mathrm{C}$ overnight.

\subsection{Prolonged Humidity Exposure}

Using saturated salt solutions as outline by Rockland et al. ${ }^{8}$ three different relative humidity chambers were made. Using Potassium Acetate, Magnesium Nitrate and Sodium Chloride at $20{ }^{\circ} \mathrm{C}$ generated $23 \%$, $54 \%$, and $75 \%$ relative humidity respectively. In each chamber, a $200 \mathrm{~mL}$ container was filled with approximately $30 \mathrm{~mL}$ of the saturated salt solution. A petri dish of a MOF was suspended above the water level to ensure vapour-MOF interaction and no liquid-MOF interaction.

\section{Isotherms}

\subsection{Pore Size Distribution Fits from Nitrogen Gas Adsorption Isotherms}

Using Micrometrics 3Flex software the pore size distributions can be fit to several different DFT models including Tarazona, cylindrical pores on oxide surface, or pillared clay. Using the standard deviation for each of these models as a determination of the goodness of fit, we picked the model that has the lowest standard deviation to represent the best fit of the models. Cells highlighted in green (Table S1-S3) illustrate the models that were used to fit the data.
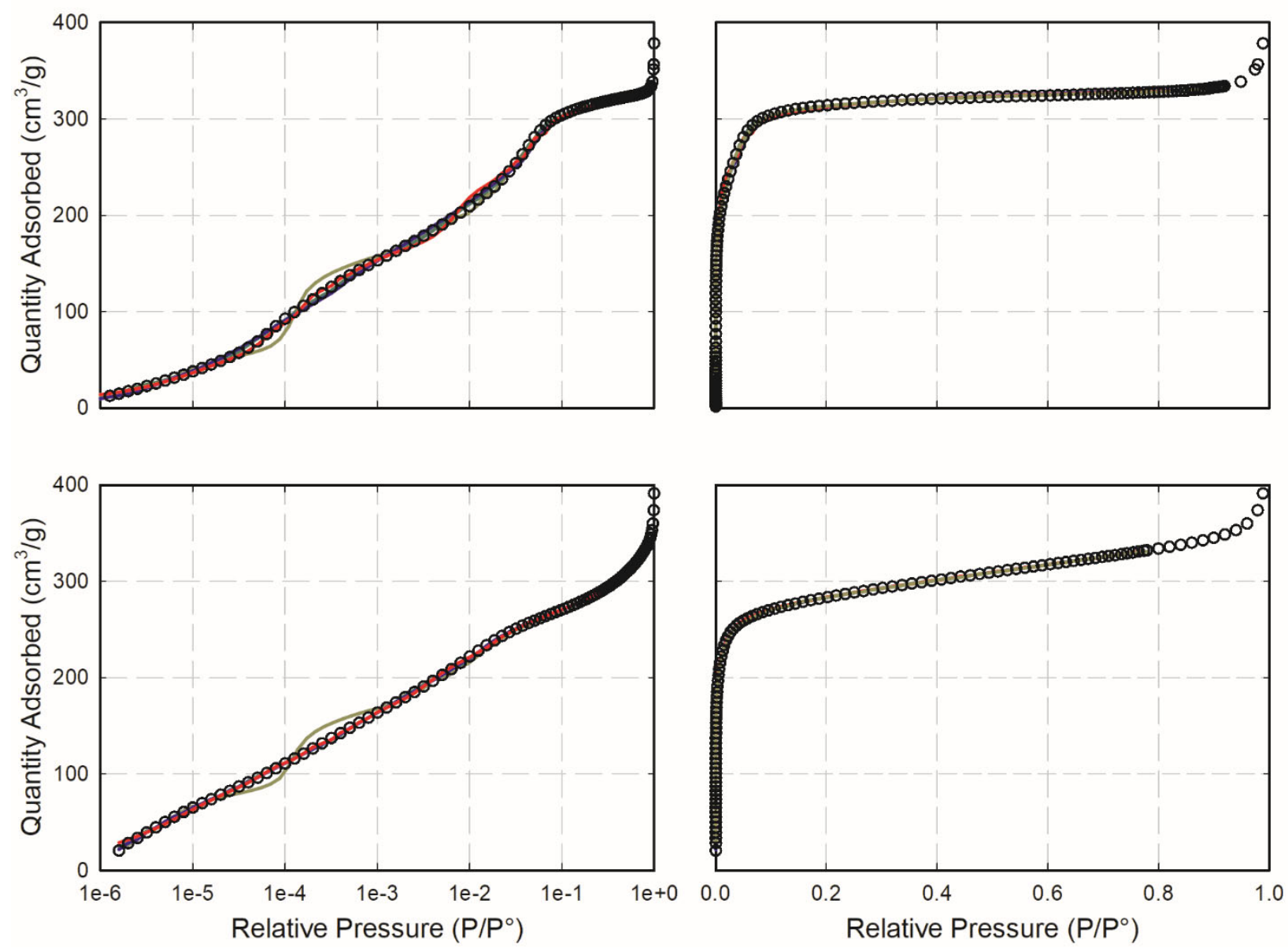

Figure S1: Pore size distribution model fits for UiO-66 (top) and UiO-66- $\mathrm{NH}_{2}$ (bottom). Red trace represents the tarazona model, blue trace is cylindrical pores on an oxide surface model, green trace represents the pillared clay model. Yellow trace represents the $\mathrm{N} 2$ at $77 \mathrm{~K}$ on carbon, slit pore, NLDFT equilibrium model. 
Supporting Information for

\section{Analysis of the Water Adsorption Isotherms in UiO-based Metal-Organic Frameworks}

Mason C. Lawrence and Michael J. Katz

Table S1: Standard deviation for pore size distribution fits of UiO-66 and UiO-66- $\mathrm{NH}_{2}$

\begin{tabular}{|c|c|c|}
\cline { 2 - 3 } \multicolumn{1}{c|}{} & UiO-66 & UiO-66-NH2 \\
\hline Tarazona & $2.99 \mathrm{~cm}^{3} / \mathrm{g}$ & $1.29 \mathrm{~cm}^{3} / \mathrm{g}$ \\
\hline Cylindrical Pores on an Oxide Surface & $2.63 \mathrm{~cm}^{3} / \mathrm{g}$ & $0.44 \mathrm{~cm}^{3} / \mathrm{g}$ \\
\hline Pillared Clay & $1.04 \mathrm{~cm}^{3} / \mathrm{g}$ & $0.98 \mathrm{~cm}^{3} / \mathrm{g}$ \\
\hline N2 at 77 K on carbon, slit pore, NLDFT equilibrium & $4.7 \mathrm{~cm}^{3} / \mathrm{g}$ & $5.1 \mathrm{~cm}^{3} / \mathrm{g}$ \\
\hline
\end{tabular}
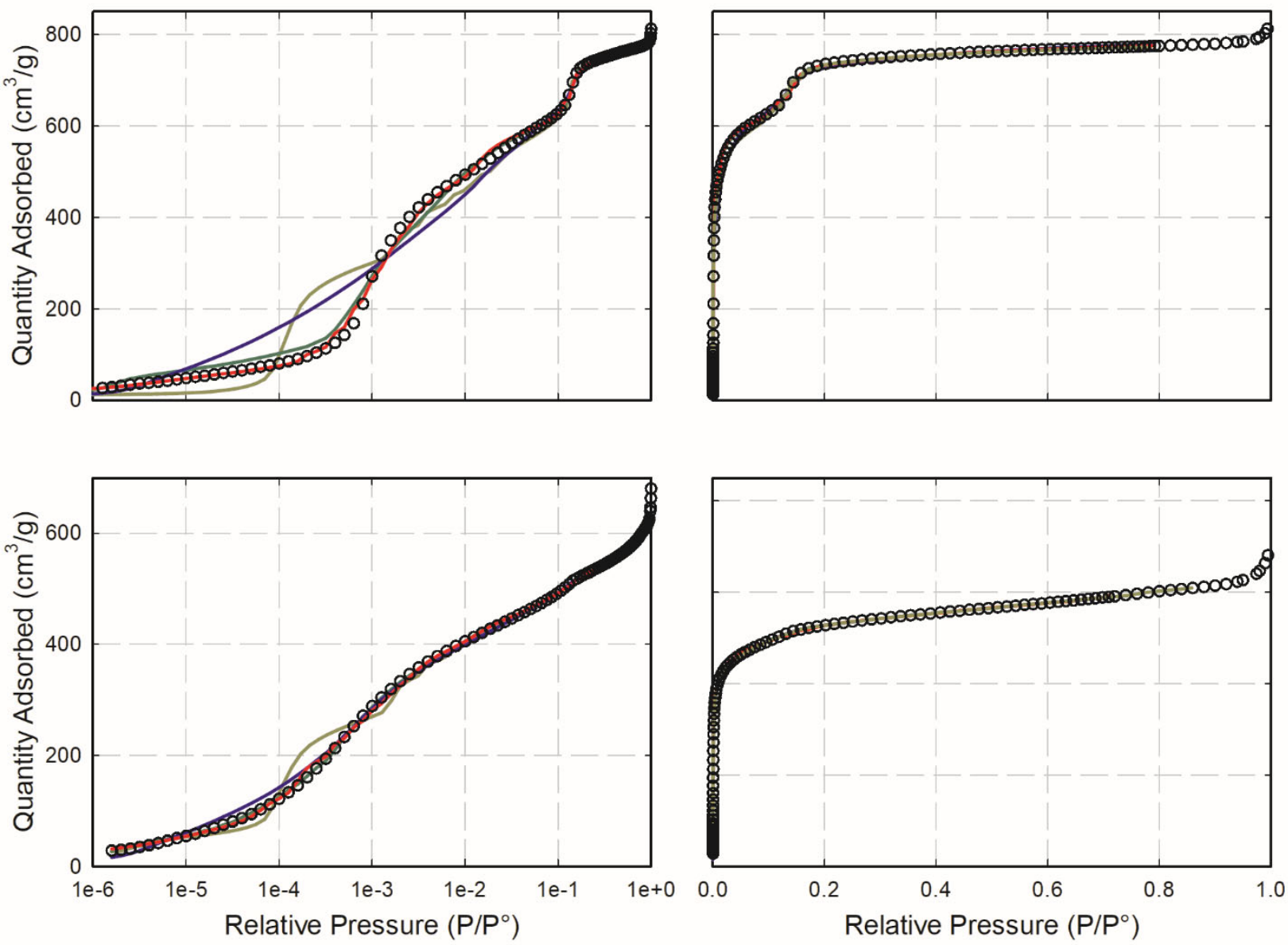

Figure S2: Pore size distribution model fits for UiO-67 (top) and UiO-67- $\mathrm{NH}_{2}$ (bottom). Red trace represents the tarazona model, blue trace is cylindrical pores on an oxide surface model, green trace represents the pillared clay model. Yellow trace represents the N2 at $77 \mathrm{~K}$ on carbon, slit pore, NLDFT equilibrium model.

Table S2: Standard deviation for Pore size Distribution Fits of UiO-67 and UiO-67- $\mathrm{NH}_{2}$

\begin{tabular}{|c|c|c|}
\cline { 2 - 3 } \multicolumn{1}{c|}{} & UiO-67 & UiO-67-NH2 \\
\hline Tarazona & $7.37 \mathrm{~cm}^{3} / \mathrm{g}$ & $3.83 \mathrm{~cm}^{3} / \mathrm{g}$ \\
\hline Cylindrical Pores on an Oxide Surface & $35.6 \mathrm{~cm}^{3} / \mathrm{g}$ & $7.47 \mathrm{~cm}^{3} / \mathrm{g}$ \\
\hline Pillared Clay & $13.2 \mathrm{~cm}^{3} / \mathrm{g}$ & $2.17 \mathrm{~cm}^{3} / \mathrm{g}$ \\
\hline N2 at 77 K on carbon, slit pore, NLDFT equilibrium & $40.4 \mathrm{~cm}^{3} / \mathrm{g}$ & $13.7 \mathrm{~cm}^{3} / \mathrm{g}$ \\
\hline
\end{tabular}


Supporting Information for

\section{Analysis of the Water Adsorption Isotherms in UiO-based Metal-Organic Frameworks}

Mason C. Lawrence and Michael J. Katz
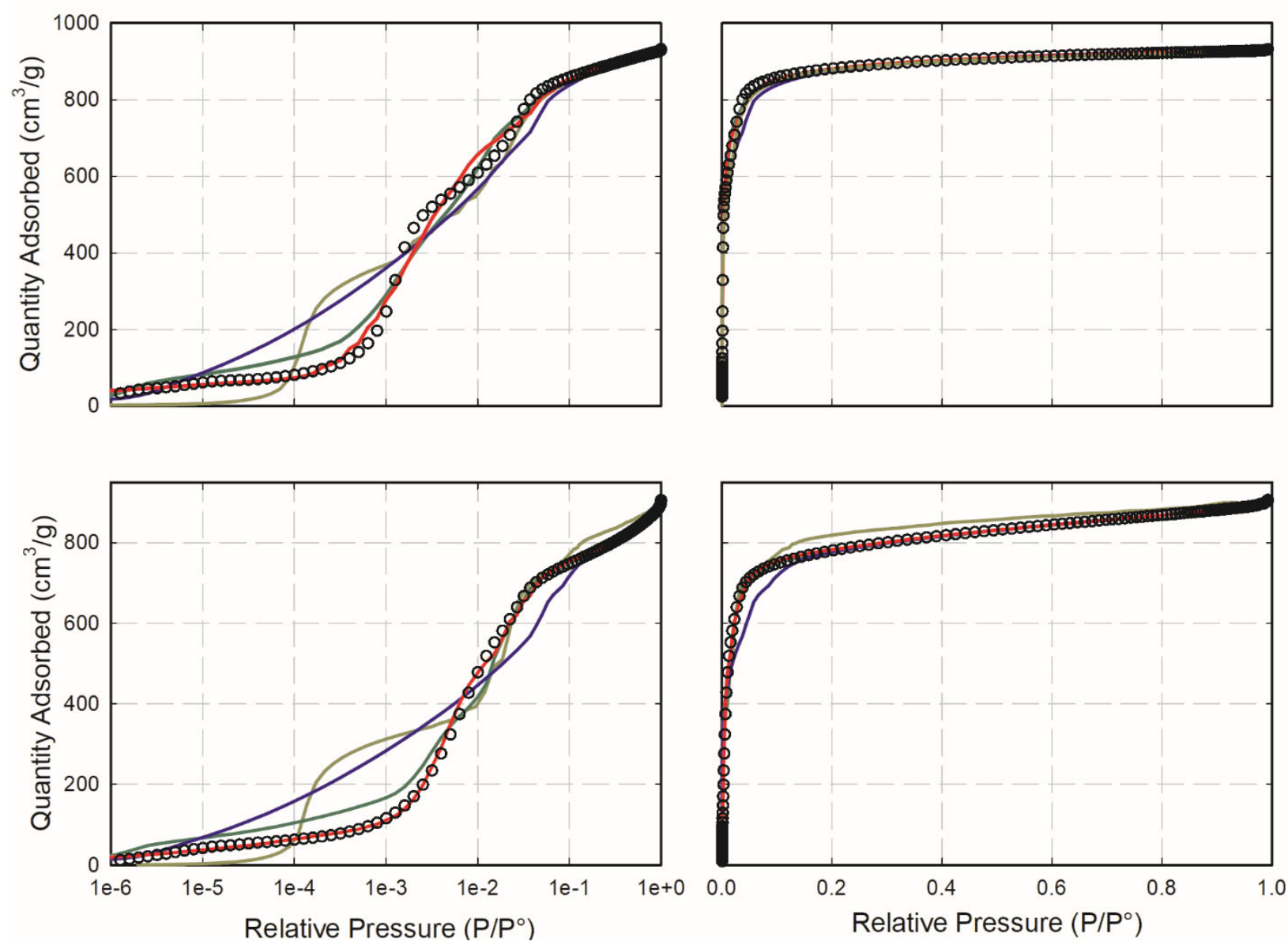

Figure S3: Pore size distribution model fits for UiO-68- $\mathrm{Me}_{4} / \mathrm{PCN}-57$ (top) and UiO-68-NH 2 (bottom). Red trace represents the tarazona model, blue trace is cylindrical pores on an oxide surface model, green trace represents the pillared clay model. Grey trace represents the $\mathrm{N} 2$ at $77 \mathrm{~K}$ on carbon, slit pore, NLDFT equilibrium model.

Table S3: Standard deviation for Pore size Distribution Fits of UiO-68-Me $4 / \mathrm{PCN}-57$ and UiO-68-NH $\mathrm{N}_{2}$

\begin{tabular}{|c|c|c|}
\hline Method A (plots in Figure S3) & UiO-68-Me $4 / \mathrm{PCN} 57$ & UiO-68-NH 2 \\
\hline Tarazona & $13.1 \mathrm{~cm}^{3} / \mathrm{g}$ & $6.1 \mathrm{~cm}^{3} / \mathrm{g}$ \\
\hline Cylindrical Pores on an Oxide Surface & $45.3 \mathrm{~cm}^{3} / \mathrm{g}$ & $69.0 \mathrm{~cm}^{3} / \mathrm{g}$ \\
\hline Pillared Clay & $19.8 \mathrm{~cm}^{3} / \mathrm{g}$ & $20.1 \mathrm{~cm}^{3} / \mathrm{g}$ \\
\hline N2 at $77 \mathrm{~K}$ on carbon, slit pore, NLDFT equilibrium & $48.2 \mathrm{~cm}^{3} / \mathrm{g}$ & $72.0 \mathrm{~cm}^{3} / \mathrm{g}$ \\
\hline \multicolumn{3}{|l|}{ Method B (plots not shown in Figure S3) } \\
\hline Tarazona & $12.0 \mathrm{~cm}^{3} / \mathrm{g}$ & $7.15 \mathrm{~cm}^{3} / \mathrm{g}$ \\
\hline Cylindrical Pores on an Oxide Surface & $35.1 \mathrm{~cm}^{3} / \mathrm{g}$ & $69.0 \mathrm{~cm}^{3} / \mathrm{g}$ \\
\hline Pillared Clay & $16.6 \mathrm{~cm}^{3} / \mathrm{g}$ & $28.9 \mathrm{~cm}^{3} / \mathrm{g}$ \\
\hline
\end{tabular}




\section{Analysis of the Water Adsorption Isotherms in UiO-based Metal-Organic Frameworks}

Mason C. Lawrence and Michael J. Katz

\subsection{Water Adsorption and Desorption Isotherms}
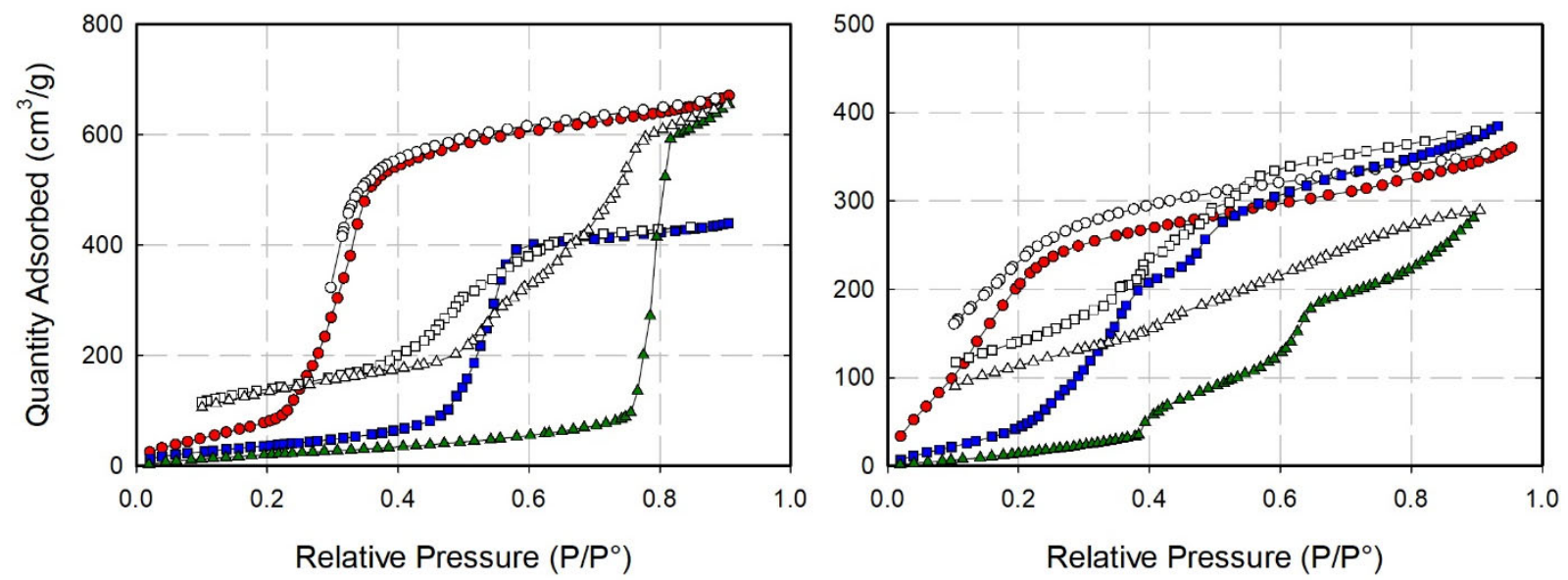

Figure S4. Water adsorption and desorption isotherms. Left: UiO-66 (Adsorption: red circle trace; Desorption: white circle trace) UiO-67 (Adsorption: blue square trace; Desorption: white square trace), and UiO-68-Me $/ \mathrm{P}_{4} \mathrm{PCN}-57$ (Adsorption: green triangle trace; Desorption: white triangle trace). Right: UiO66- $\mathrm{NH}_{2}$ (Adsorption: red circle trace; Desorption: white circle trace) UiO-67- $\mathrm{NH}_{2}$ (Adsorption: blue square trace; Desorption: white square trace), and $\mathrm{UiO}-68-\mathrm{NH}_{2}$ (Adsorption: green triangle trace; Desorption: white triangle trace) 


\section{Analysis of the Water Adsorption Isotherms in UiO-based Metal-Organic Frameworks}

Mason C. Lawrence and Michael J. Katz

\subsection{Pore Size Distributions from Nitrogen Gas and Water Vapour Adsorption Isotherms.}
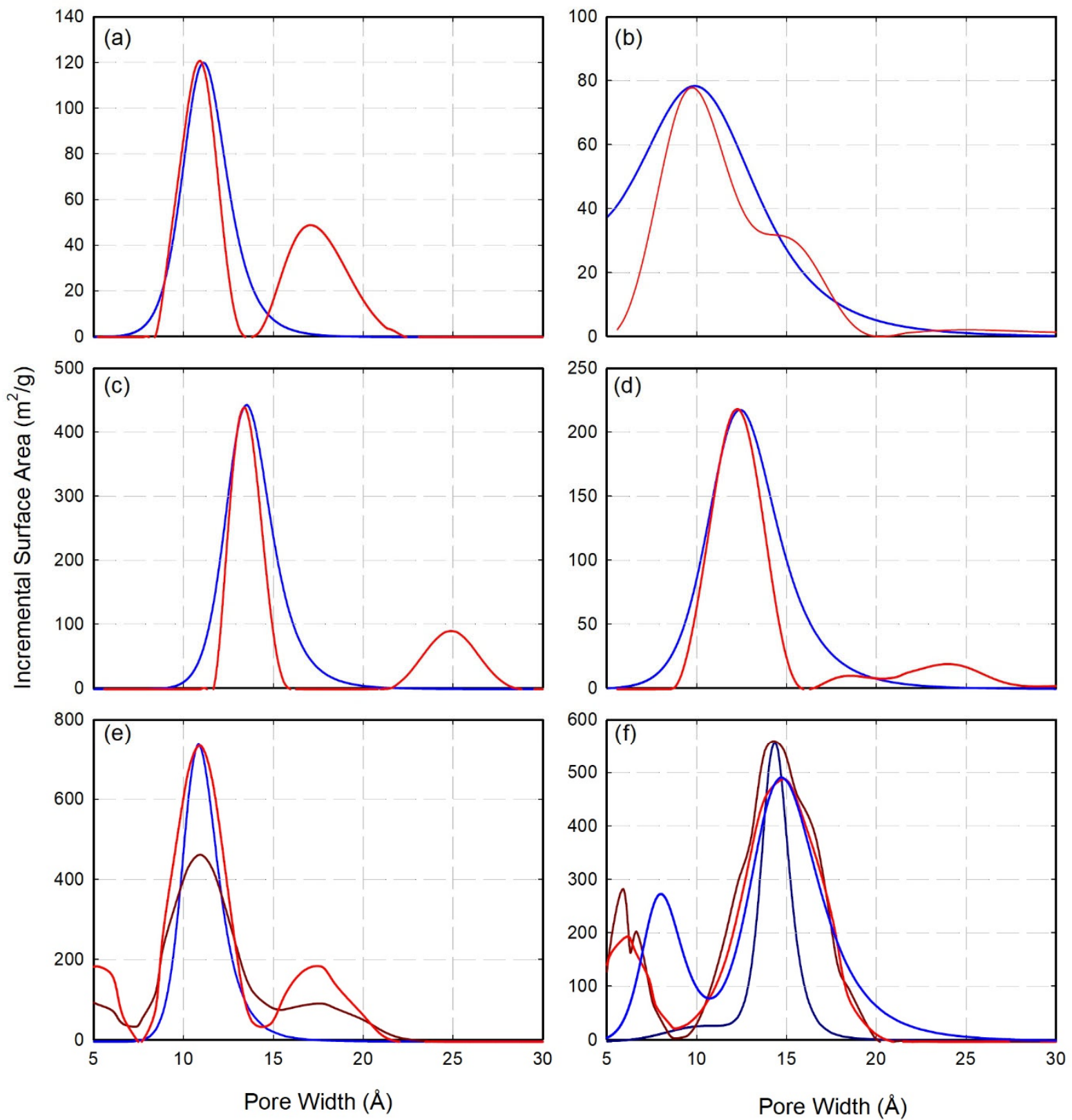

Figure S5: Comparison of DFT-determined pore size distributions from fits to the nitrogen gas adsorption isotherm (red trace) and the pore size distribution fits from the Kelvin equation-derived water va-

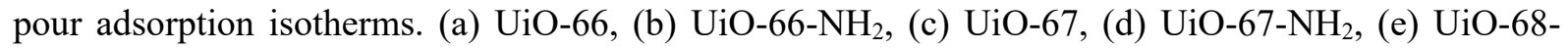
$\mathrm{Me}_{4} / \mathrm{PCN}-57$ (Dark red and dark blue are from synthetic method B), (f) UiO-68- $\mathrm{NH}_{2}$ (Dark red and dark blue are from synthetic method B). Note: the pore size fits for UiO-68-Me $4 / \mathrm{PCN}-57$ and $\mathrm{UiO}-68-\mathrm{NH}_{2}$ are not perfect fits, but it does predict the most predominant pore. 


\section{Analysis of the Water Adsorption Isotherms in UiO-based Metal-Organic Frameworks}

Mason C. Lawrence and Michael J. Katz

\subsection{Water Adsorbed per Zirconium Centre}
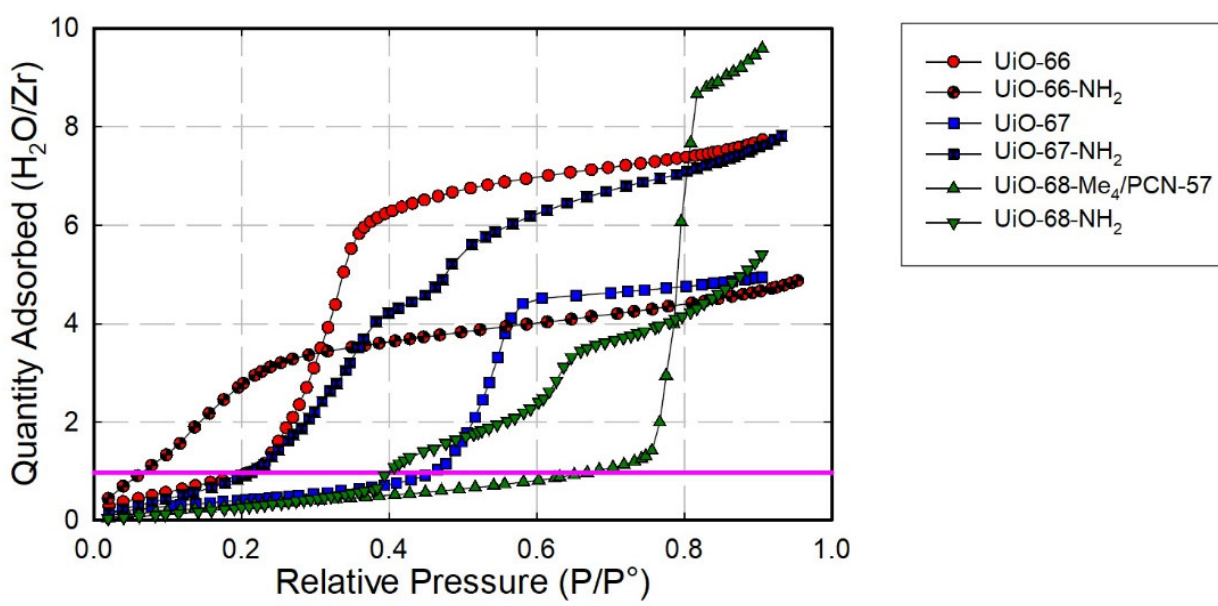

Figure S6: Water adsorbed per zirconium as a function or pressure. Pink line indicates one $\mathrm{H}_{2} \mathrm{O}$ per zirconium centre.

\subsection{Isosteric Heats of Adsorption of Water on UiO-66}

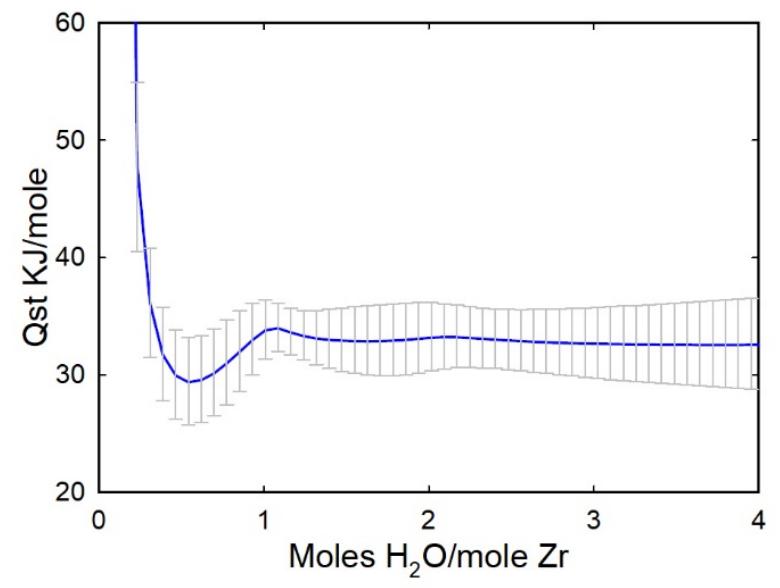

Figure S7: Isosteric heats of adsorption of water adsorbed onto UiO-66. The error bars are derived from the error associated with the slope of the fit to the Clausius Clapeyron equation.

\subsection{Comparison of water isotherms for UiO-68 synthetic procedures.}

Over the course of the manuscript, several synthetic procedures for $\mathrm{UiO}-68-\mathrm{Me}_{4} / \mathrm{PCN}-57$ and $\mathrm{UiO}-68$ $\mathrm{NH}_{2}$ were attempted. In our hands, we struggled to get reproducible results. The two synthetic preps (Method A and Method B) were often successful, but occasionally still failed. This suggests that there are additional variables in the synthesis of this MOF that are yet unknown that prevent us from getting reproducible results. Furthermore, the data for these materials were different enough that warrant discussion of these differences. Given that others may also get differing results, we opted to report on the results of two different synthetic procedures to shed light on the MOF itself. Table S4 shows the differences in the observed BET surface areas. Method B produces materials with notably $\left(\sim 400 \mathrm{~m}^{2} / \mathrm{g}\right)$ lower surface area than Method A. despite this, the pore size distributions for the two MOFs (Figure S5 e and $\mathrm{f}-\mathrm{red} /$ dark red traces) seem more similar than different. This may suggest that Method A produces fewer impurities. However, given the quality of the pore size distribution fits, we are hesitant to overinterpret this data. 
Supporting Information for

\section{Analysis of the Water Adsorption Isotherms in UiO-based Metal-Organic Frameworks}

Mason C. Lawrence and Michael J. Katz

Table S4: Comparison of BET surface areas between Method A and Method B for the UiO-68 reported in this work.

\begin{tabular}{|c|c|c|c|}
\cline { 2 - 4 } \multicolumn{1}{c|}{} & \multicolumn{3}{c|}{ BET surface area $\left(\mathbf{m}^{2} / \mathbf{g}\right)$} \\
\hline MOF & Method A & Method B & Expected \\
\hline UiO-68-Me $4 /$ PCN-57 & 3475 & 2950 & $3300^{6}$ \\
\hline UiO-68-NH & 3350 & 2950 & $3750^{9}$ \\
\hline
\end{tabular}

Despite the similarities in the nitrogen adsorption data, the water isotherms looked surprisingly different. For UiO-68-Me $\mathrm{MeN}_{4} \mathrm{PCN}-57$, the two methods had different condensation step positions. This suggests either a change in the hydrophobicity of the MOF, potentially via conformational changes, or the difference in defect density, which could change the pore size. Based on the pore size distribution data, it seems unlikely that the pore size is changing. Figure S8, which shows the water adsorption swing data demonstrate that over the course of the adsorption/desorption swings, the condensation step for UiO68-Me 4 /PCN-57 produced via Method A shifts to higher relative humidity. This suggests that a conformational change may be occurring due to the water in the MOF which produce a larger average pore size.

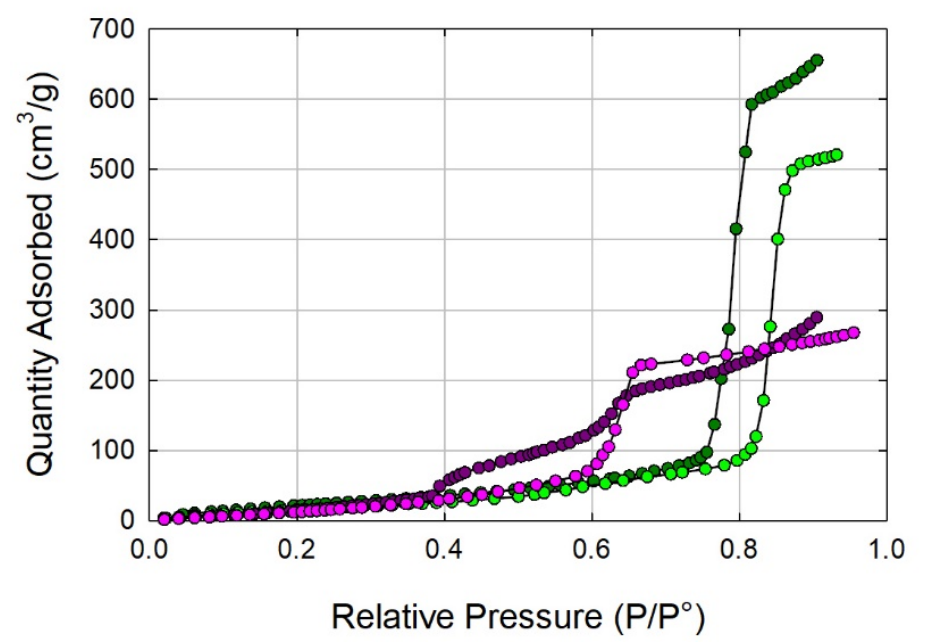

Figure S8: water adsorption isotherms for UiO-68-Me $4 / \mathrm{PCN}-57$ (Dark green: method A; Light green: method B) and UiO-68- $\mathrm{NH}_{2}$ (Magenta: method A; Pink: method B).

Looking at the water adsorption isotherm for UiO-68- $\mathrm{NH}_{2}$ there are two steps in the isotherm for Method A, but only one step for Method B. upon closer inspection of the isotherm from method B, the background slope changes around $0.4 \mathrm{P} / \mathrm{P}^{\mathrm{o}}$. This suggests that both MOFs have the same types of pores, but the number of each pore may be different. From the data in this work, we assumed that the condensation step at $0.6 \mathrm{P} / \mathrm{P}^{\circ}$ is the large octahedral pore and access to the tetrahedral pore may only be possible in the synthesis for Method A. Indeed, if we look at the pore size distribution generated from the water adsorption isotherms, we see two pores consistent with the tetrahedral and octahedral pore of UiO-68.

Although the interpretation of this data is consistent with the data, given that the synthetic procedures weren't as reproducible for the UiO-68 MOFs vs. the UiO-66 and UiO-67 MOFs, this is only a hypothesis. Further analysis of the synthetic procedures is necessary to optimize the procedures and analyze the water adsorption/desorption data; this is beyond the scope of this work. 


\section{Supporting Information for}

Analysis of the Water Adsorption Isotherms in UiO-based Metal-Organic Frameworks

Mason C. Lawrence and Michael J. Katz

\subsection{Water adsorption/desorption swing isotherms.}

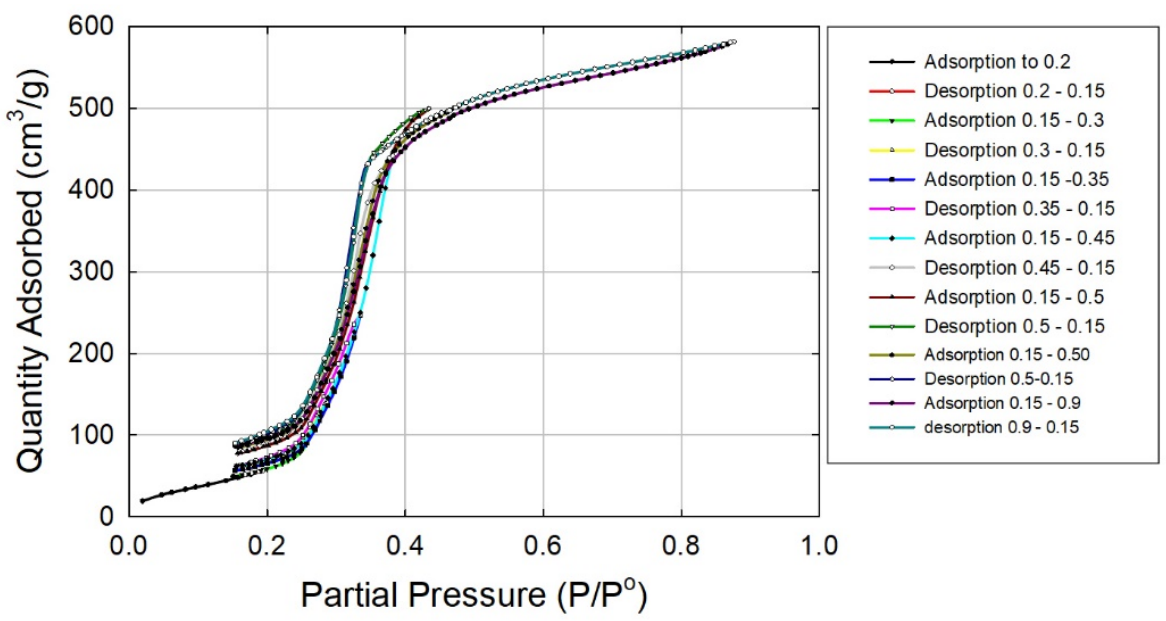

Figure S9: water adsorption/desorption swings for UiO-66

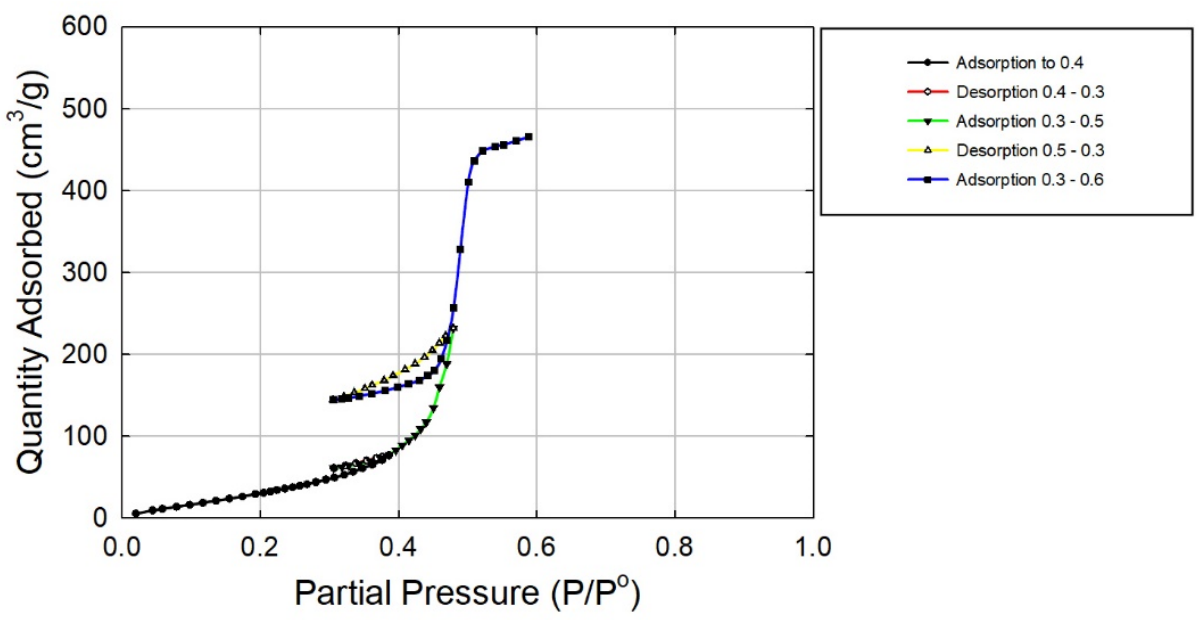

Figure S10: water adsorption/desorption swings for UiO-67

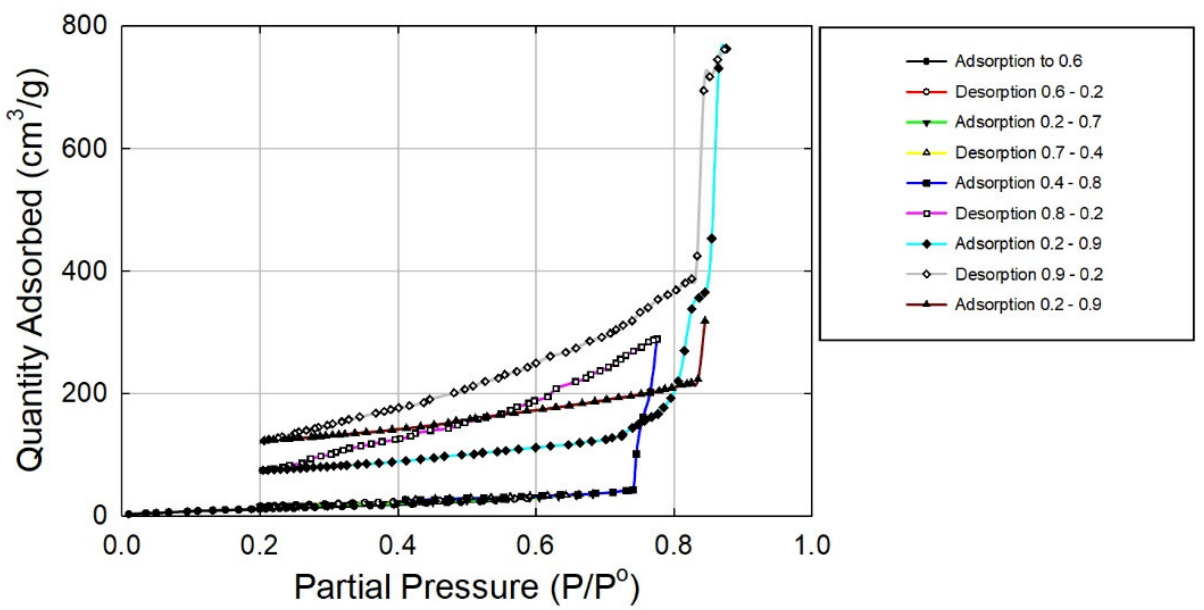

Figure S11: water adsorption/desorption swings for UiO-68-Me $4 / \mathrm{PCN}-57$ 
Supporting Information for

\section{Analysis of the Water Adsorption Isotherms in UiO-based Metal-Organic Frameworks}

Mason C. Lawrence and Michael J. Katz

\section{Water Isotherm Models}

\subsection{Water Adsorption Fits}

UiO-66, UiO-66- $\mathrm{NH}_{2}$, and $\mathrm{UiO}-67$ were fit to the following equation:

$$
Q_{\text {Adsorbed }}=q_{\max 1} \frac{1}{1+e^{\frac{-\left(P-P_{\text {cond } 1}\right)}{\beta 1}}}+m P+b \quad \mathbf{S 1}
$$

For UiO-67- $\mathrm{NH}_{2}$, UiO-68-Me4/PCN-57, and UiO-68- $\mathrm{NH}_{2}$ a dual-site equation was utilized:

$$
Q_{\text {Adsorbed }}=q_{\max 1} \frac{1}{1+e^{\frac{-\left(P-P_{\text {cond } 1)}\right.}{\beta 1}}}+q_{\max 2} \frac{1}{1+e^{\frac{-\left(P-P_{\text {cond }}\right)}{\beta 2}}}+m P+b \mathbf{S 2}
$$

In Equation (S1) and (S2), $\mathrm{q}_{\max 1} / \mathrm{q}_{\max 2}$ represents the saturation loading of water, $\mathrm{P}$ represents the partial pressure, $P_{\text {cond } 1} / P_{\text {cond2 }}$ represents the centre of the adsorption step, $\beta 1 / \beta 2$ relate to the width of the peak. To account for the pre pore filling stage, a function $\mathrm{f}(\mathrm{P})=\mathrm{mP}+\mathrm{b}$ was used. Low pressure data where the linear regime was not well fit were cut out to ensure a good fit for the condensation step.

Table S5: Fit results for single site and dual site water adsorption isotherms.

\begin{tabular}{|l|c|c|c|c|c|c|c|}
\hline \multicolumn{1}{|c|}{ MOF } & $\begin{array}{c}\mathbf{q}_{\text {sat1 }} \\
\left(\mathbf{c m}^{\mathbf{3}} / \mathbf{g}\right)\end{array}$ & $\begin{array}{c}\mathbf{P}_{\text {cond1 }} \\
(\mathbf{R H})\end{array}$ & $\begin{array}{c}\boldsymbol{\beta 1} \\
(\mathbf{R H})\end{array}$ & $\begin{array}{c}\mathbf{q}_{\text {sat2 }} \\
\left(\mathbf{c m}^{\mathbf{3}} / \mathbf{g}\right)\end{array}$ & $\begin{array}{c}\mathbf{P}_{\text {cond2 }} \\
(\mathbf{R H})\end{array}$ & $\begin{array}{c}\boldsymbol{\beta 2} \\
(\mathbf{R H})\end{array}$ & $\mathbf{R}^{\mathbf{2}}$ \\
\hline UiO-66 & $436(11)$ & $30.95(10)$ & $0.0268(10)$ & -- & -- & -- & 0.9995 \\
\hline UiO-66-NH & $223(2)$ & $11.94(13)$ & $0.0569(11)$ & -- & -- & -- & 0.9993 \\
\hline UiO-67 & $310(5)$ & $52.89(8)$ & $0.0209(8)$ & -- & -- & -- & 0.9986 \\
\hline UiO-67-NH $_{2}$ & $139(6)$ & $32.4(3)$ & $0.037(2)$ & $48(4)$ & $49.9(5)$ & $0.021(4)$ & 0.9995 \\
\hline $\begin{array}{l}\text { UiO-68-Me } \\
\text { PCN-57 } \\
\text { (Mehtod B) }\end{array}$ & $534(3)$ & $79.00(3)$ & $0.0111(3)$ & -- & -- & -- & 0.999 \\
\hline $\begin{array}{l}\text { UiO-68-Me } \\
\text { PCN-57 } \\
(\text { Method A) }\end{array}$ & $84(15)$ & $79(3)$ & $0.128(16)$ & $407(3)$ & $84.360(10)$ & $0.00794(10)$ & 1.0000 \\
\hline $\begin{array}{l}\text { UiO-68- NH } \\
\text { (Method A) }\end{array}$ & $78(5)$ & $41.6(4)$ & $0.034(4)$ & $102(5)$ & $62.1(2)$ & $0.025(2)$ & 0.997 \\
\hline $\begin{array}{l}\text { UiO-68- NH } \\
\text { (Method B) }\end{array}$ & $42(10)$ & $54(2)$ & $0.0546(12)$ & $143(7)$ & $63.62(5)$ & $0.0100(7)$ & 0.9994 \\
\hline
\end{tabular}

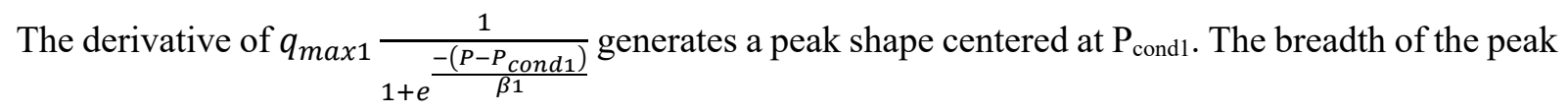
was determined by calculating the FWHM using the fityk software suite using a pearson VII peak shape. 


\section{Analysis of the Water Adsorption Isotherms in UiO-based Metal-Organic Frameworks}

Mason C. Lawrence and Michael J. Katz

\subsection{Isosteric heats of adsorption}

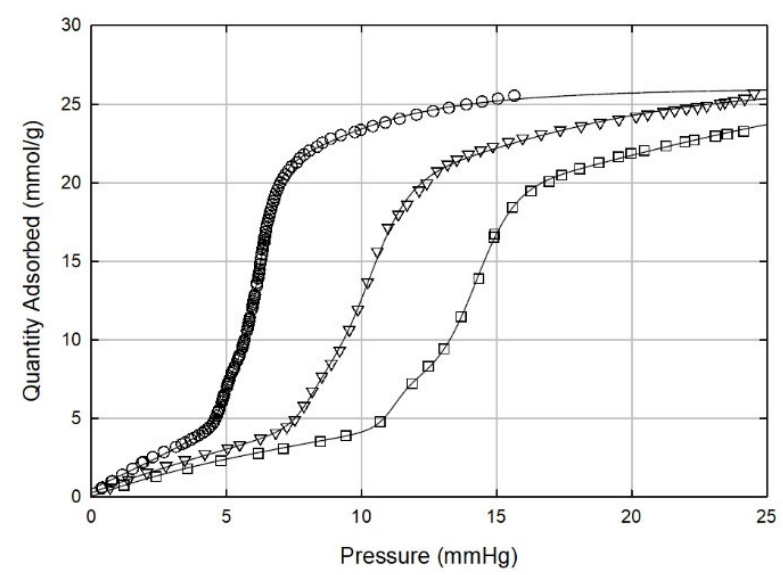

Figure S12: Water adsorption isotherms of UiO-66 measured at $295 \mathrm{~K}$ (circles), $305 \mathrm{~K}$ (triangles), and $315 \mathrm{~K}$ (squares) and their associated fits.

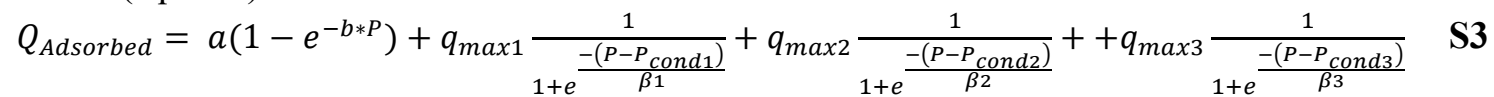

Although for isosteric heats of adsorption a chemically meaningful equation is rightfully used, any equation which fits the data well and interpolates between the data points is sufficient to determine the isosteric heats of adsorption. Thus, for isosteric heats of adsorption, the three water isotherms were fit using the equation above. The parameters $\mathrm{a}, \mathrm{q}_{\max 1}, \mathrm{q}_{\max 2}$, and $\mathrm{q}_{\max 3}$ were forced to being identical for all 3 temperature; this is a chemically reasonable restraint that states the number of each absorption sites stay constant across the temperature range explored. Furthermore, this enabled us to better fit the low-pressure data necessary to determine the isosteric heats at low loadings. The isosteric loadings were numerically determined. The Clausius Clapeyron equation was used to determine the isosteric heats of adsorption. The error for the isosteric heats of adsorption were determined from the error of the slope from the Clausius Clapeyron equation. This was performed in Excel. 
Supporting Information for

Analysis of the Water Adsorption Isotherms in UiO-based Metal-Organic Frameworks

Mason C. Lawrence and Michael J. Katz

\section{Thermogravimetric Analysis}

Thermogravimetric analysis was run on a TA instruments Q500, heating under air with a flow rate of $50 \mathrm{~mL} / \mathrm{min}$ starting at room temperature until $650^{\circ} \mathrm{C}$ at a rate of $10^{\circ} \mathrm{C} / \mathrm{min}$. The number of linkers incorporated was demined as outlined by Lillerud et al..$^{10}$

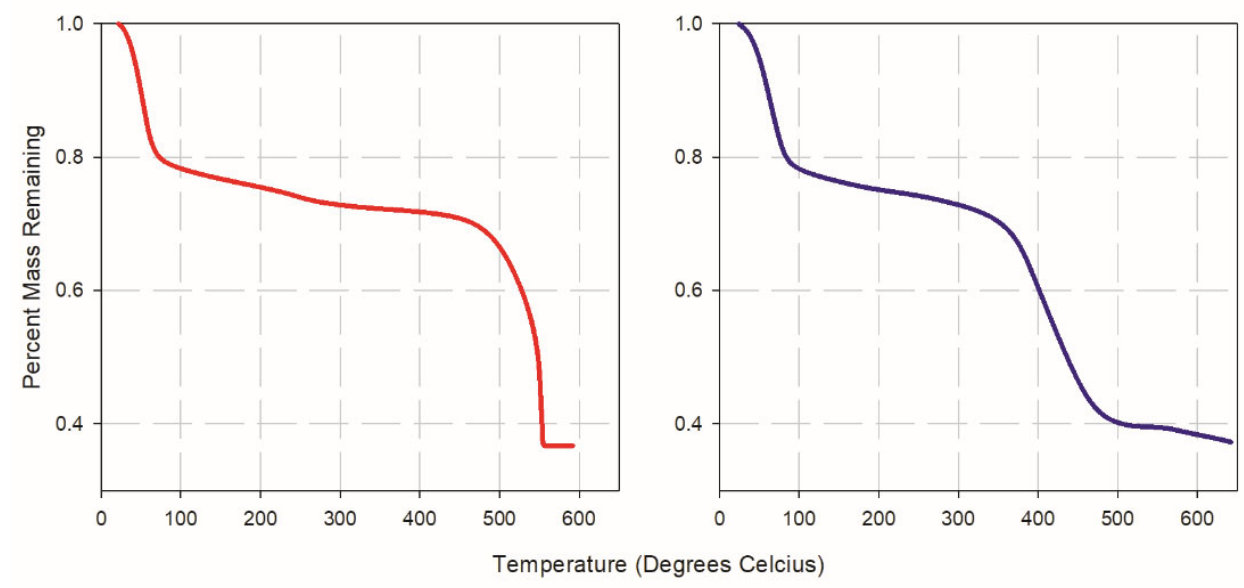

Figure S13: TGA of UiO-66 (left) and UiO-66- $\mathrm{NH}_{2}$ (right).

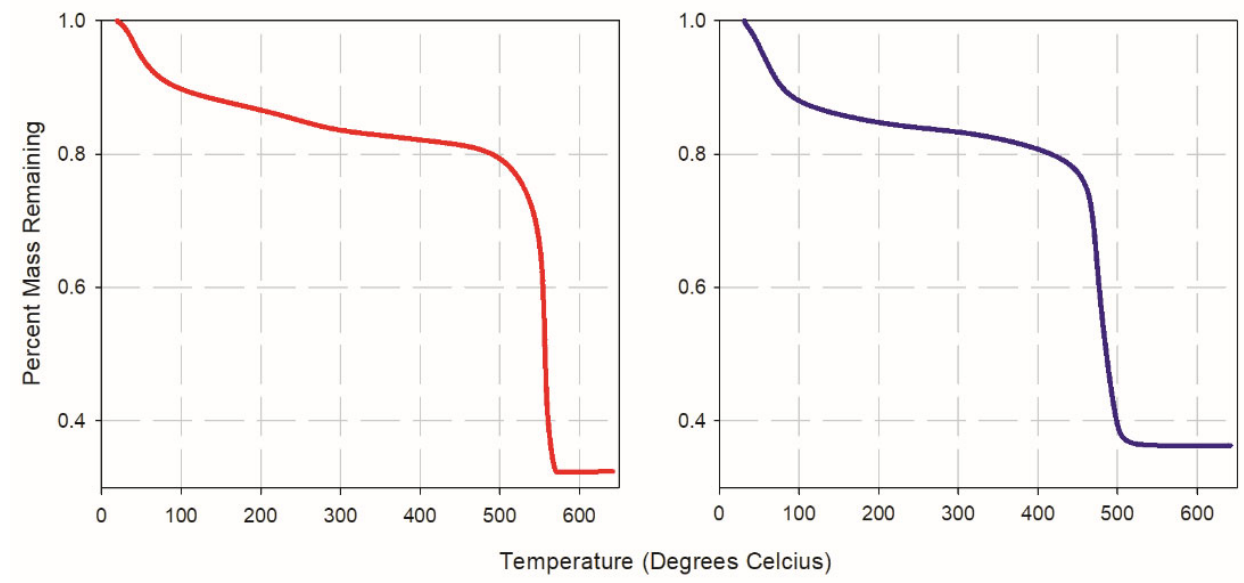

Figure S14: TGA of UiO-67 (left) and UiO-67-- $\mathrm{NH}_{2}$ (right). 


\section{Analysis of the Water Adsorption Isotherms in UiO-based Metal-Organic Frameworks}

Mason C. Lawrence and Michael J. Katz

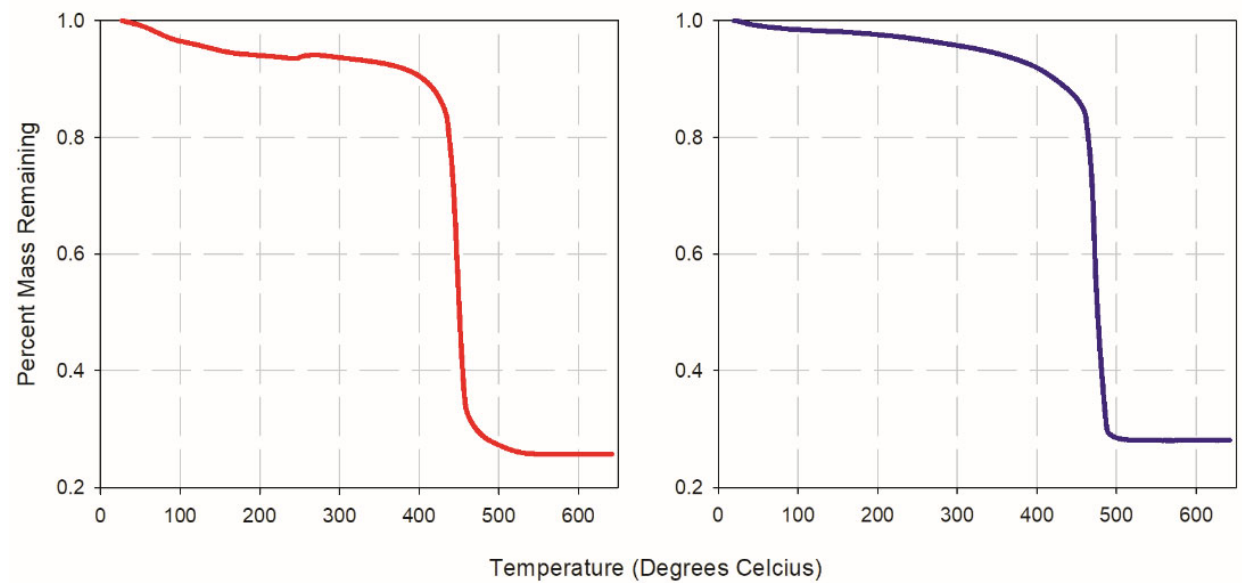

Figure S15: TGA of UiO-68-Me $4 / \mathrm{PCN}-57$ (left) and UiO-68- $\mathrm{NH}_{2}$ (right). The mass increase seen in UiO-68-Me $/$ /PCN-57 has been seen in multiple samples, and consistent with the results published by Klet et. al. ${ }^{11}$

The number of linkers incorporated was demined as outlined by Lillerud et al. ${ }^{10}$ Briefly, the heating of the MOF can be described by the following chemical equation (assuming no defects):

$$
\mathrm{Zr}_{6} \mathrm{O}_{4}(\mathrm{OH})_{4}(\mathrm{BDC})_{6}+45 \mathrm{O}_{2} \stackrel{\Delta}{\rightarrow} 6 \mathrm{ZrO}_{2}+48 \mathrm{CO}_{2}+14 \mathrm{H}_{2} \mathrm{O}
$$

At temperatures above approximately $350{ }^{\circ} \mathrm{C}$ the MOF becomes dehydrated and can be represented by the following chemical equation (assuming no defects):

$$
\mathrm{Zr}_{6} \mathrm{O}_{6}(\mathrm{BDC})_{6}+43 \mathrm{O}_{2} \stackrel{\Delta}{\rightarrow} 6 \mathrm{ZrO}_{2}+48 \mathrm{CO}_{2}+12 \mathrm{H}_{2} \mathrm{O}
$$

The molar mass of $\mathrm{ZrO}_{2}$ is $123.22 \mathrm{~g} / \mathrm{mol}$, but the mole ratio from the above equation is a 1:6 MOF to $\mathrm{ZrO}_{2}$ which would require us to use a molar mass of $123.22 \mathrm{~g} / \mathrm{mol}$. The molar mass of the dehydrated MOF is $1628.03 \mathrm{~g} / \mathrm{mol}$. From this information we can find the theoretical plateau for a MOF containing 6 linkers if the normalized the mass of the leftover $\mathrm{ZrO}_{2}$ to $100 \%$ (also know as the end plateau) the idea plateau for the MOF would be found by the following equation:

$$
\text { Ideal Plateau }=\left(\frac{\text { Mass MOF analyzed }}{6 * \text { Molar Mass } \mathrm{ZrO}_{2}}\right) * 100 \% \quad \mathbf{S 4}
$$

This equation gives the ideal plateau for UiO-66 to be $220 \%$. As shown in Figure S16 we see the observed plateau to be $193 \%$. The differences between these the experimental and theoretical percent are related to the number of defects. 
Supporting Information for

\section{Analysis of the Water Adsorption Isotherms in UiO-based Metal-Organic Frameworks}

Mason C. Lawrence and Michael J. Katz

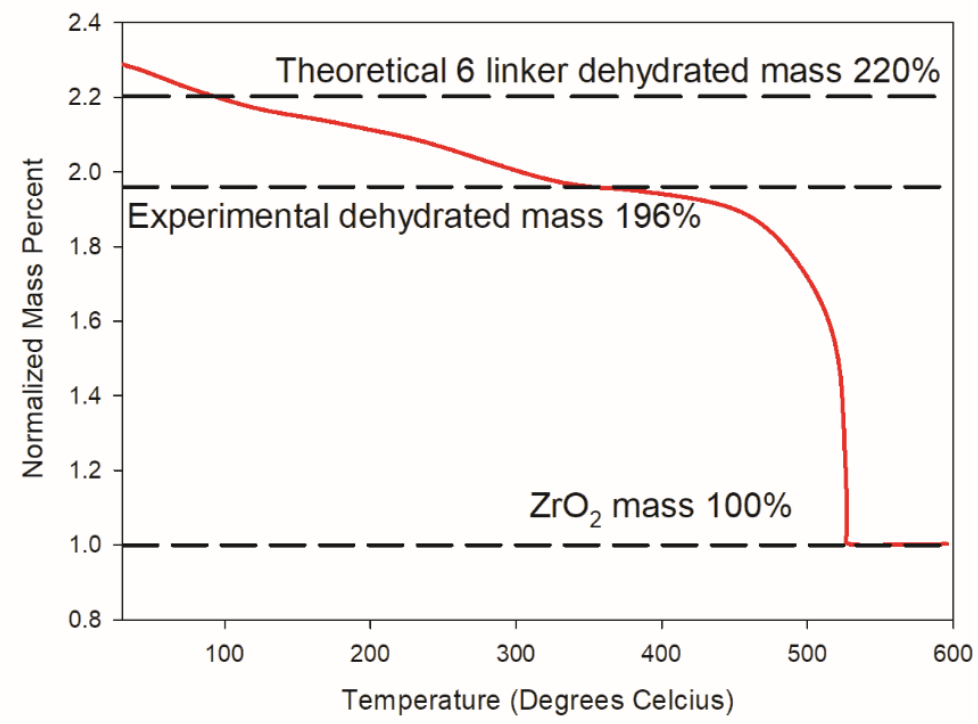

Figure S16: TGA of UiO-66 with the mass of remaining $\mathrm{ZrO}_{2}$ normalized to $100 \%$.

To determine the number of missing ligands the following formula needs to be used:

$$
\text { Thereotical Plateau }=\frac{(\text { Ideal Plateau }- \text { End Plateau })}{\text { Number of Ligands in Ideal MOF }} \quad \mathbf{5 5}
$$

We know the ideal plateau to be $220 \%$, the end plateau to be $100 \%$ and the ideal number of ligands in the MOF to be 6 to give the theoretical plateau to be $20 \%$.

To find the number of linkers present the following formula can be used where $x$ represents the number of defects. From the known formula of the UiO family of MOFs we know the ideal number of ligands is 6 . Subtracting $x$ form 6 will give the number of ligands incorporated in the MOF.

$$
\begin{gathered}
\begin{array}{c}
\text { Number of Ligands }=6-x \quad \text { S6 } \\
x=\frac{\text { Experimental Plateau }- \text { End Plateau }}{\text { Theroetical Plateau }}
\end{array} \quad \text { S7 }
\end{gathered}
$$

Solving this for UiO-66 gives the value of $x$ to be 1.2 meaning there was 4.8 ligands. 
Supporting Information for

Analysis of the Water Adsorption Isotherms in UiO-based Metal-Organic Frameworks

Mason C. Lawrence and Michael J. Katz

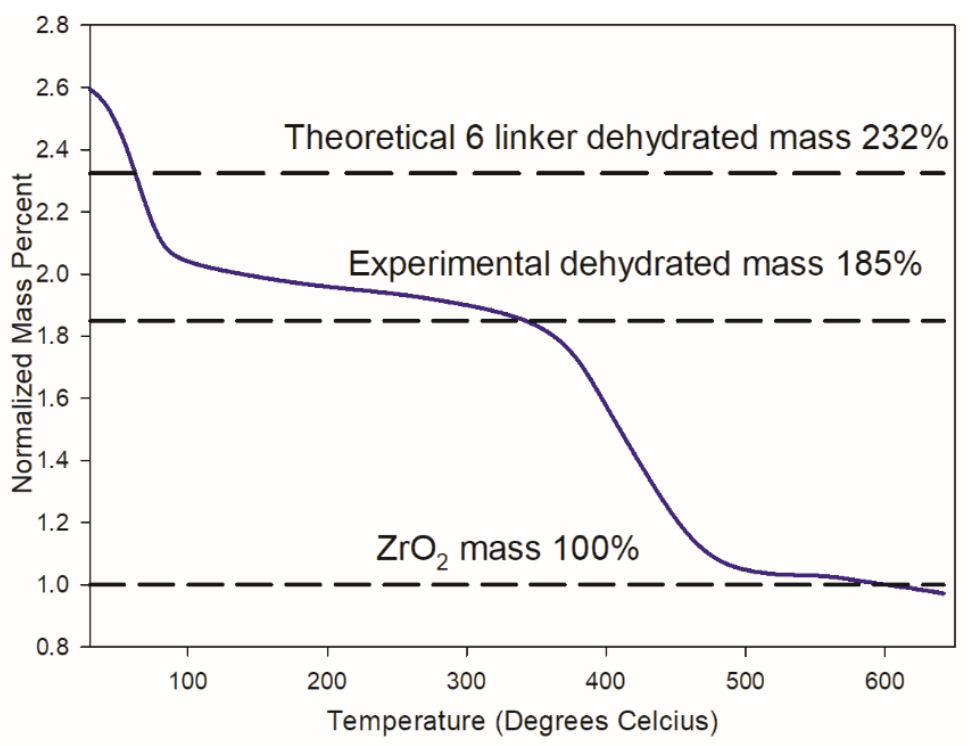

Figure S17: TGA of UiO-66- $\mathrm{NH}_{2}$ with the mass of remaining $\mathrm{ZrO}_{2}$ normalized to $100 \%$.

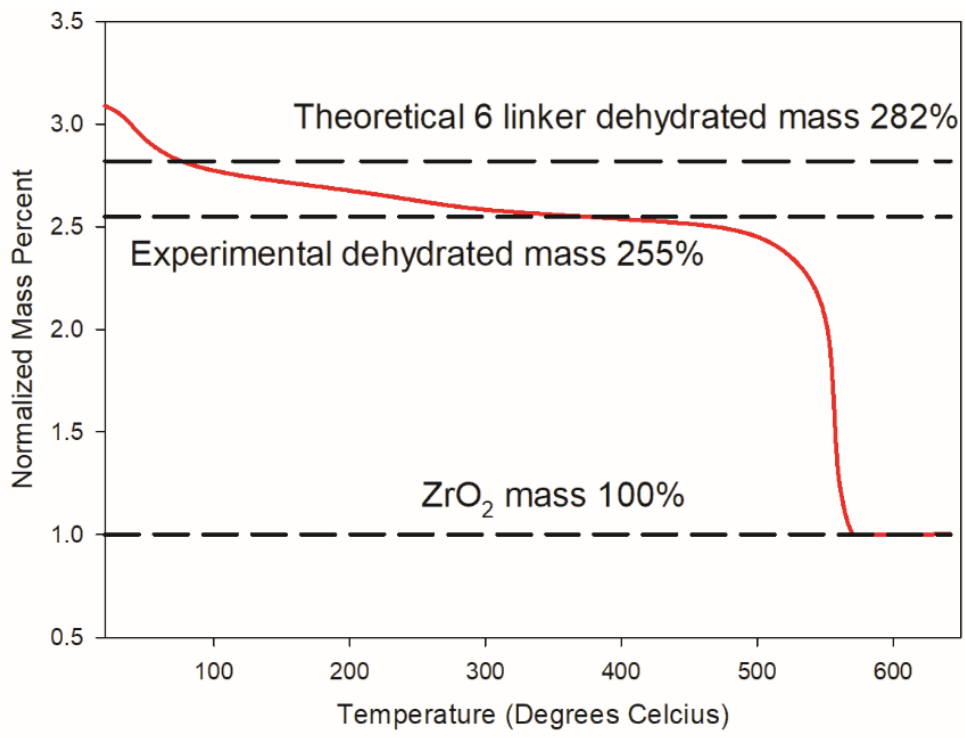

Figure S18: TGA of UiO-67 with the mass of remaining $\mathrm{ZrO}_{2}$ normalized to $100 \%$. 
Supporting Information for

Analysis of the Water Adsorption Isotherms in UiO-based Metal-Organic Frameworks

Mason C. Lawrence and Michael J. Katz

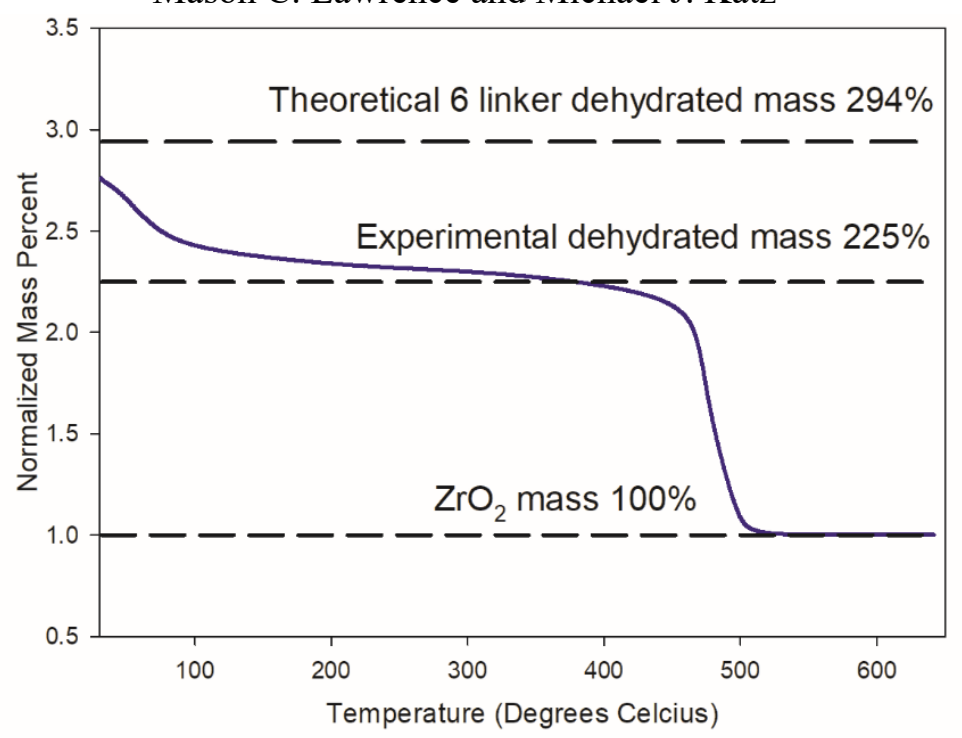

Figure S19: TGA of UiO-67- $\mathrm{NH}_{2}$ with the mass of remaining $\mathrm{ZrO}_{2}$ normalized to $100 \%$.

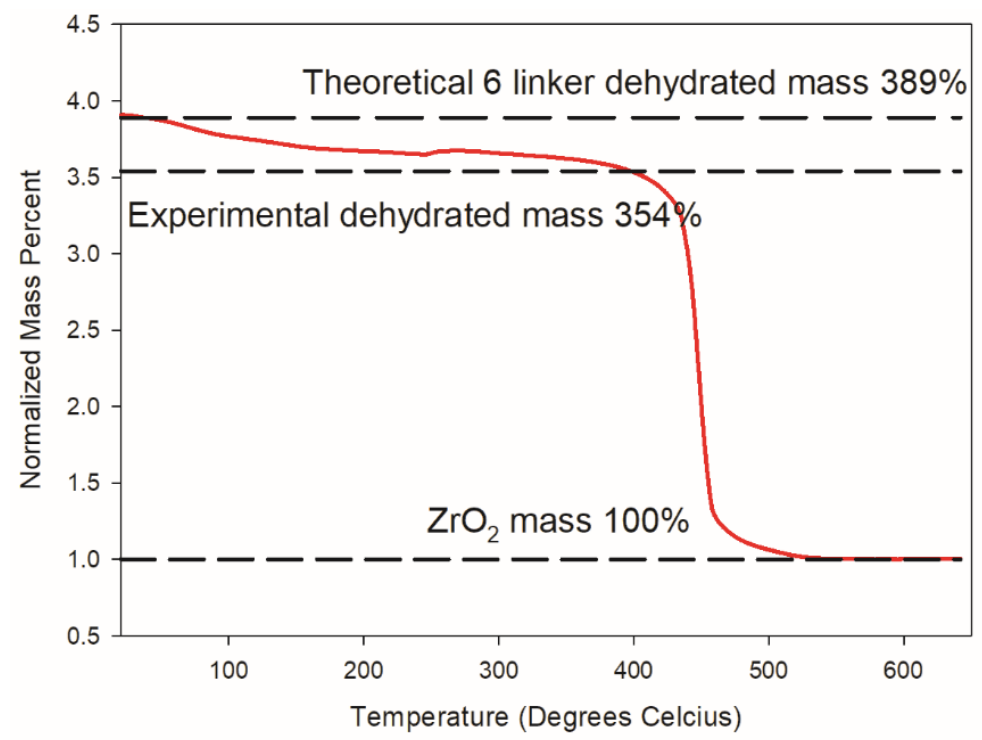

Figure S20: TGA of UiO-68-Me $/$ PCN-57 with the mass of remaining $\mathrm{ZrO}_{2}$ normalized to $100 \%$. 
Supporting Information for

Analysis of the Water Adsorption Isotherms in UiO-based Metal-Organic Frameworks

Mason C. Lawrence and Michael J. Katz

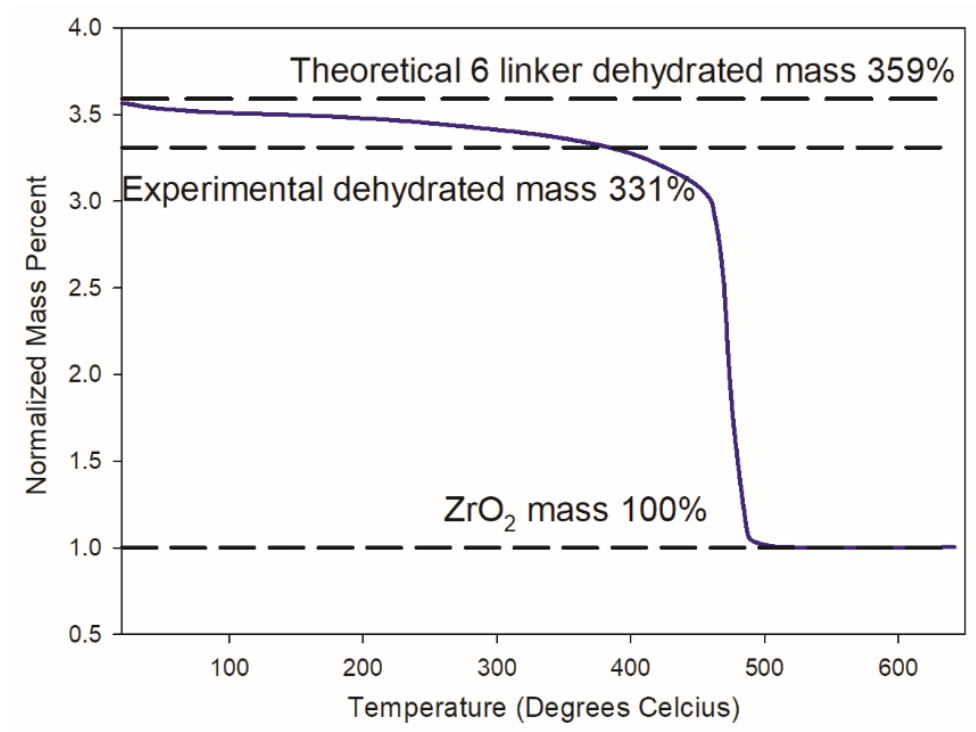

Figure S21: TGA of UiO-68- $\mathrm{NH}_{2}$ with the mass of remaining $\mathrm{ZrO}_{2}$ normalized to $100 \%$.

\section{Powder X-ray Diffraction}

Powder X-ray diffractograms were measured on a Rigaku XtalLAB Synergy-S X-ray diffractometer with a copper radiation source with the divergent slits set to $86 \%$. Patterns were measured from $3^{\circ}$ to $50^{\circ}$ in $2 \theta$. Simulated patters were obtained from literature for comparison. ${ }^{10,12-13}$ Samples were exposed to relative humidity below the large step seen in the water isotherm and powder X-ray diffractograms were collected afterwards.

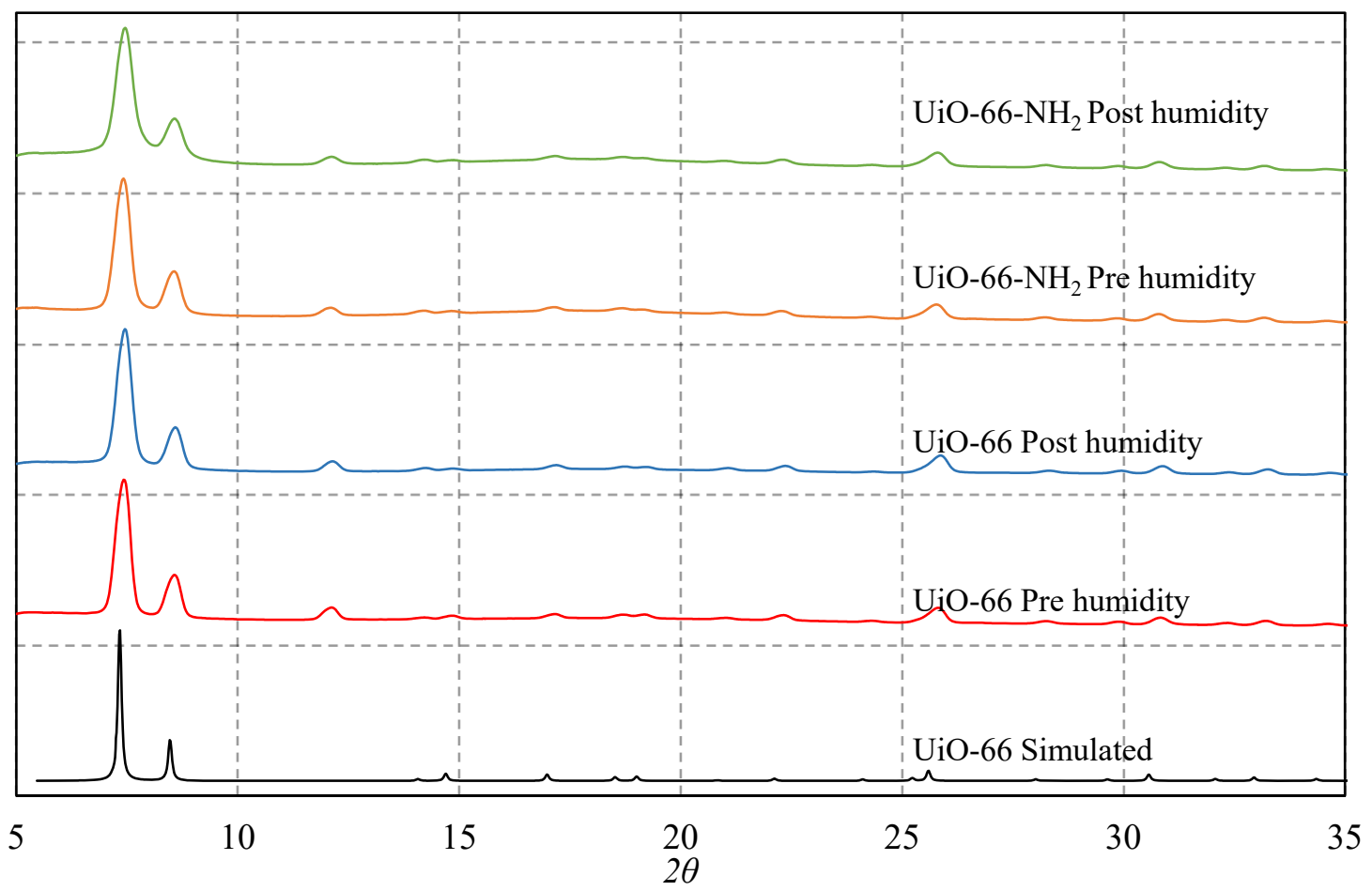

Figure S22: Powder X-ray diffraction patterns of UiO-66 and UiO-66- $\mathrm{NH}_{2}$ before and after being exposed to humidity levels below the large step in the water isotherm. 
Supporting Information for

Analysis of the Water Adsorption Isotherms in UiO-based Metal-Organic Frameworks

Mason C. Lawrence and Michael J. Katz

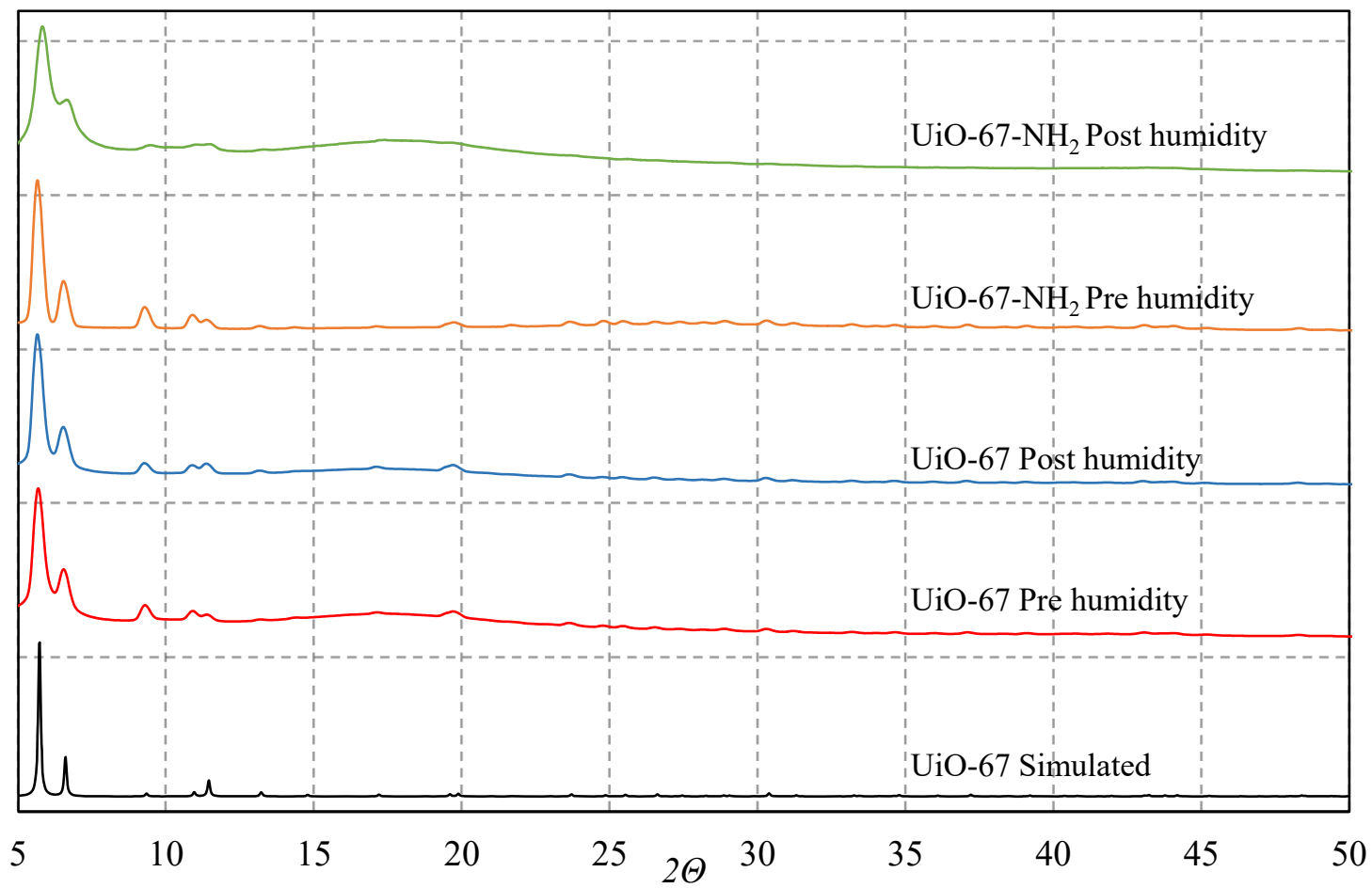

Figure S23: Powder X-ray diffraction patterns of UiO-67 and $\mathrm{UiO}-67-\mathrm{NH}_{2}$ before and after being exposed to humidity levels below the large step in the water isotherm.

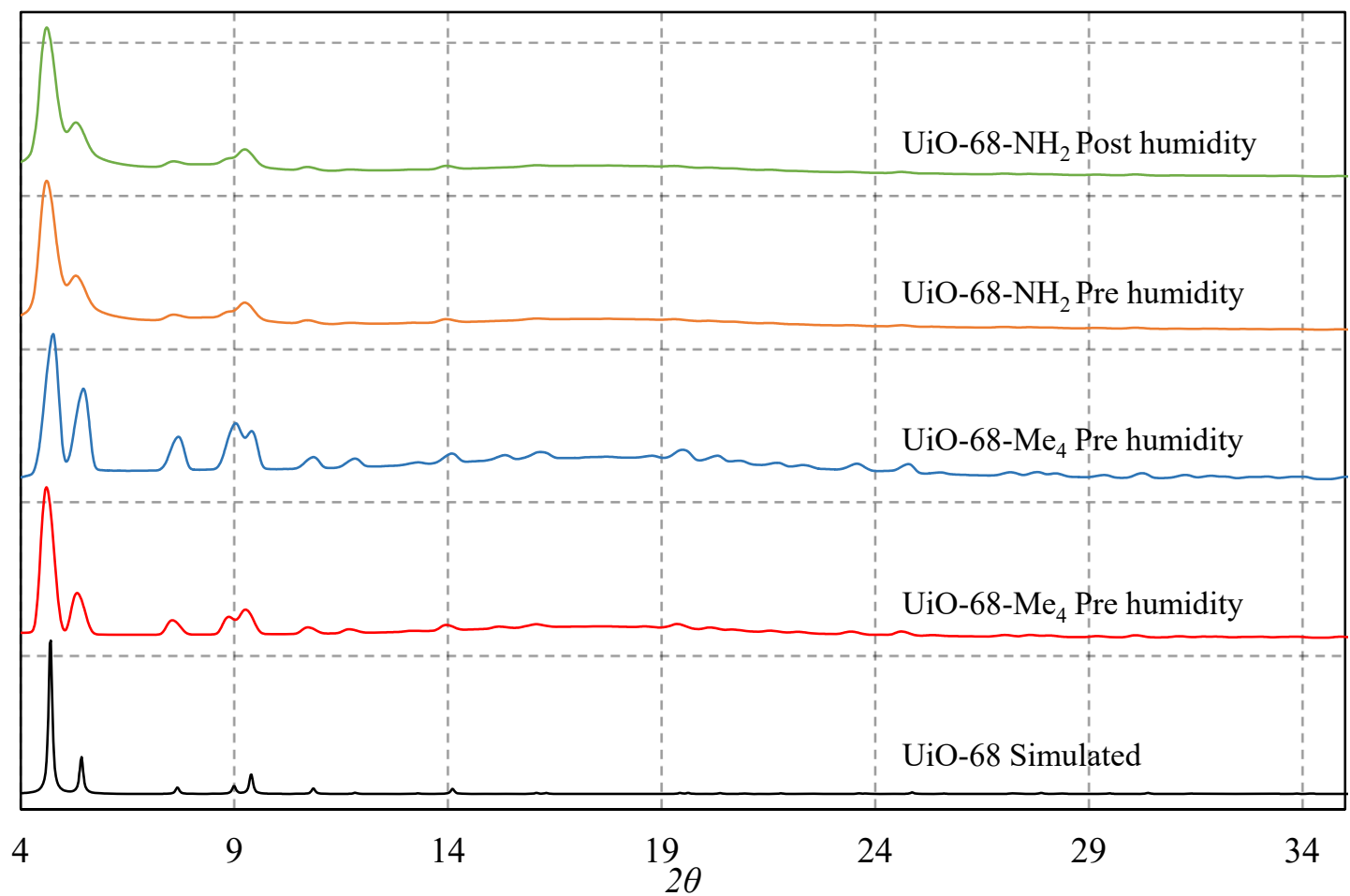

Figure S24: Powder X-ray diffraction patterns of UiO-68-Me $4 / \mathrm{PCN}-57$ and UiO-68-NH 2 before and after being exposed to humidity levels below the large step in the water isotherm 
Supporting Information for

Analysis of the Water Adsorption Isotherms in UiO-based Metal-Organic Frameworks

Mason C. Lawrence and Michael J. Katz

\section{Argon Isotherms}

Argon Isotherms were measured on a Micrometrics 3Flex at $77 \mathrm{~K}$. The data was fit using micrometrics 3Flex software to obtain the DFT pore size distributions.
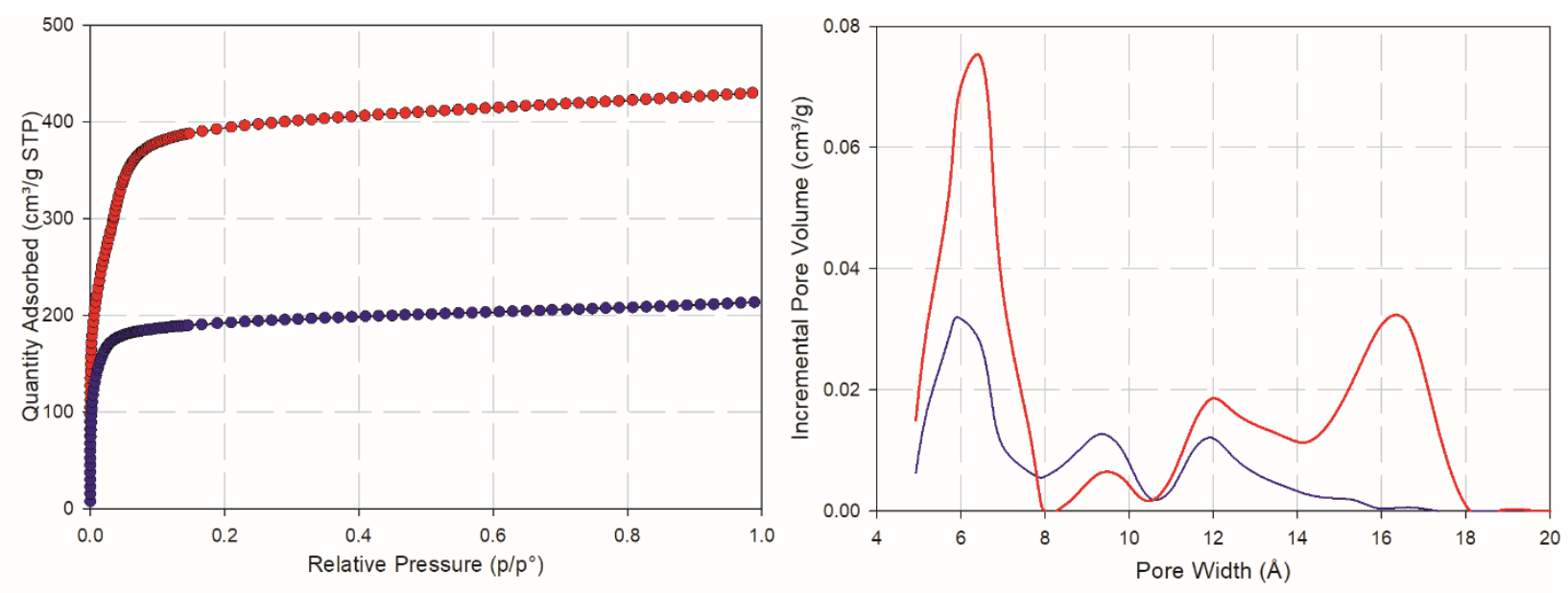

Figure S25: (left) Argon isotherms measured at $77 \mathrm{~K}$ of UiO-66 and UiO-66- $\mathrm{NH}_{2}$ in red and blue traces respectively. (right) DFT pore size distribution of UiO-66 (red) and $\mathrm{UiO}-67-\mathrm{NH}_{2}$ (blue).
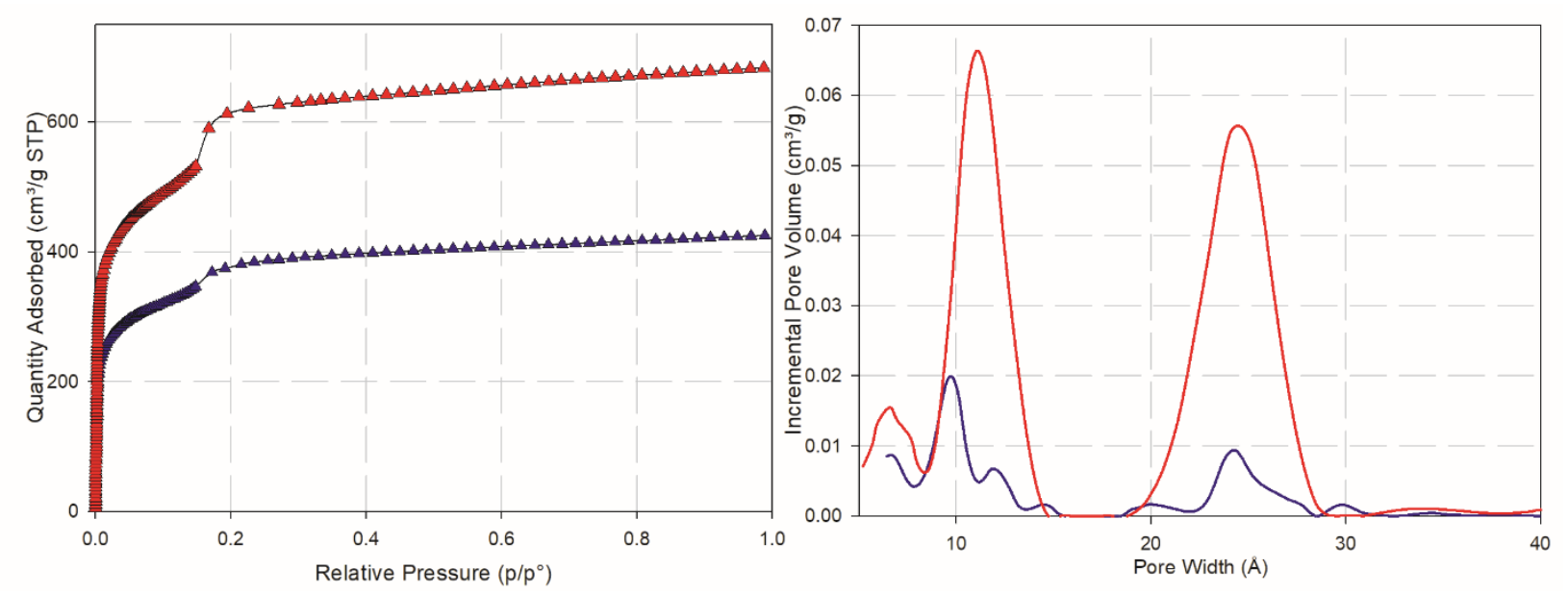

Figure S26: (left) Argon isotherms measured at $77 \mathrm{~K}$ of $\mathrm{UiO}-67$ and $\mathrm{UiO}-67-\mathrm{NH}_{2}$ in red and blue traces respectively. (right) DFT pore size distribution of UiO-67 (red) and $\mathrm{UiO}-67-\mathrm{NH}_{2}$ (blue). 


\section{Analysis of the Water Adsorption Isotherms in UiO-based Metal-Organic Frameworks}

Mason C. Lawrence and Michael J. Katz
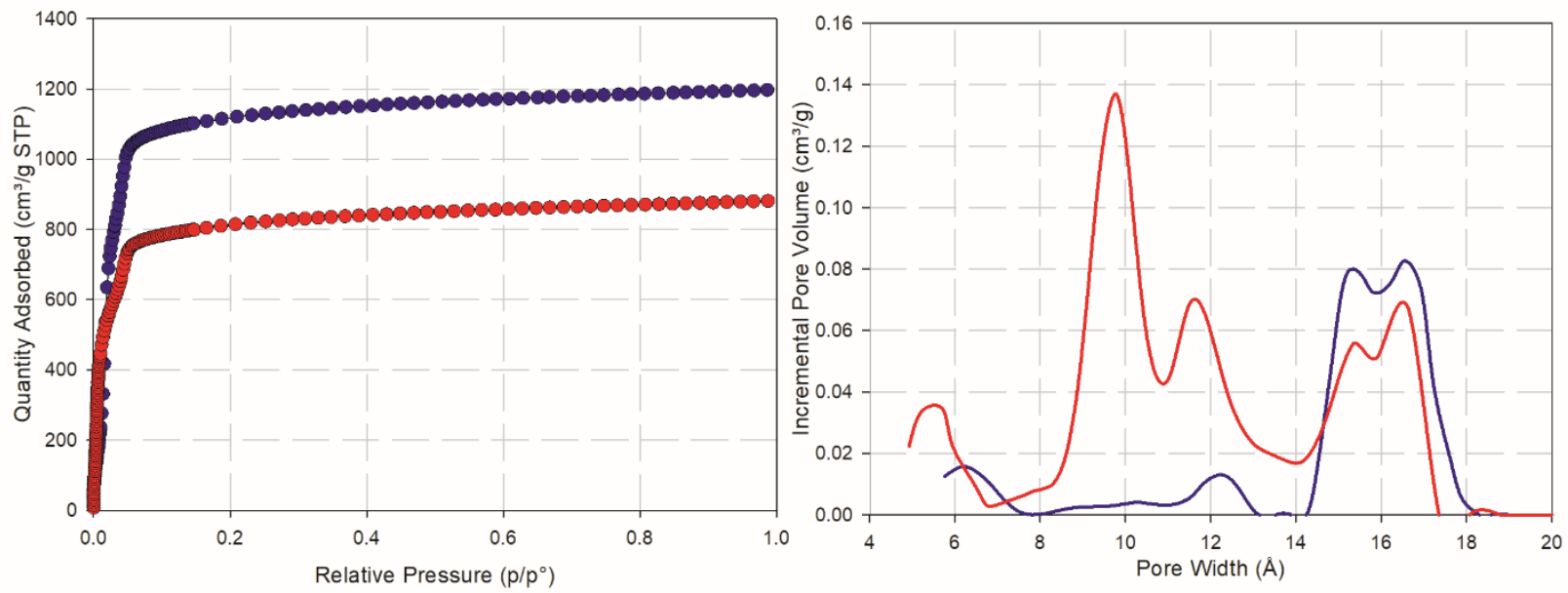

Figure S27: (left) Argon isotherms measured at 77K of UiO-67 and UiO-67- $\mathrm{NH}_{2}$ in red and blue traces respectively. (right) DFT pore size distribution of UiO-67 (red) and UiO-67- $\mathrm{NH}_{2}$ (blue).

\section{Prolonged Humidity Exposure Isotherms}

To determine the change in surface area of the UiO- $68-\mathrm{NH}_{2}$ was exposed to $54 \%$ relative humidity for 100 days. After the 100 days, the MOF were removed from the relative humidity environment, activated and measured as previously outlined. As illustrated by figure S28 there was very little change in the gas uptake capacity.

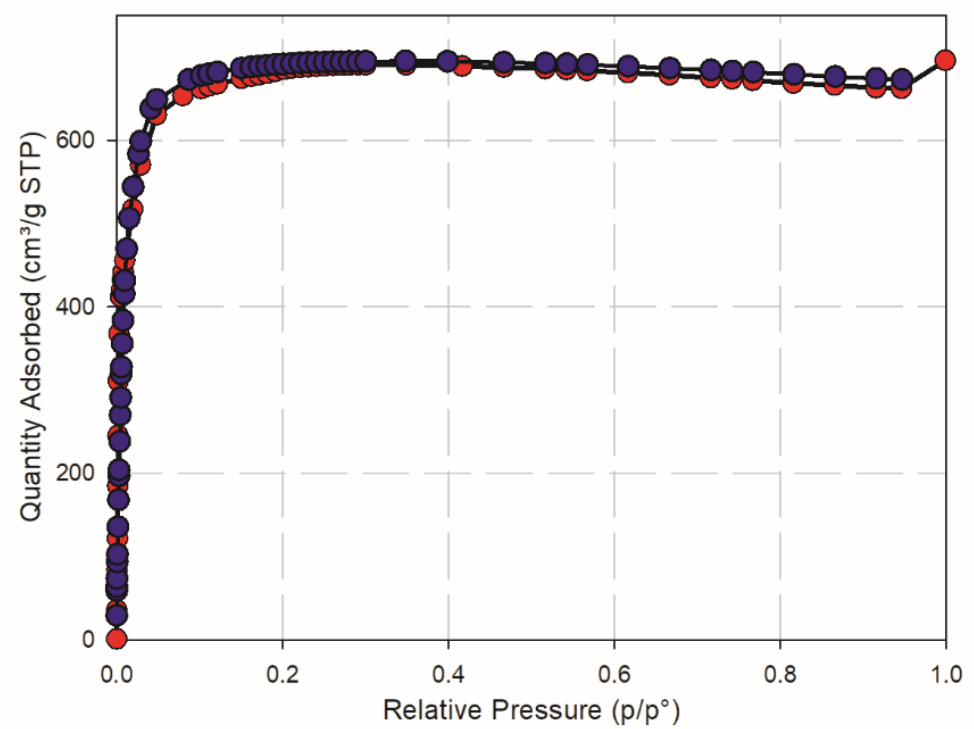

Figure S28: Nitrogen uptake at $77 \mathrm{~K}$ for $\mathrm{UiO}-68-\mathrm{Me}_{4} / \mathrm{PCN}-57$ exposed to $54 \%$ relative humidity for 100 days (Red) and fresh synthesized UiO-68-Me $4 / \mathrm{PCN}-57$.

\section{References}

(1) Cao, C.-C.; Chen, C.-X.; Wei, Z.-W.; Qiu, Q.-F.; Zhu, N.-X.; Xiong, Y.-Y.; Jiang, J.-J.; Wang, D.; Su, C.-Y. Catalysis through Dynamic Spacer Installation of Multivariate Functionalities in Metal-Organic Frameworks, J. Am. Chem. Soc. 2019, 141, 2589-2593. DOI: 10.1021/jacs.8b12372. 


\section{Analysis of the Water Adsorption Isotherms in UiO-based Metal-Organic Frameworks}

Mason C. Lawrence and Michael J. Katz

(2) Liu, Y.; Chen, Y.-P.; Liu, T.-F.; Yakovenko, A. A.; Raiff, A. M.; Zhou, H.-C. Selective Gas Adsorption and Unique Phase Transition Properties in a Stable Magnesium Metal-Organic Framework Constructed from Infinite Metal Chains, CrystEngComm 2013, 15, 9688-9693. DOI: 10.1039/C3CE41106K.

(3) Jiang, H.-L.; Feng, D.; Liu, T.-F.; Li, J.-R.; Zhou, H.-C. Pore Surface Engineering with Controlled Loadings of Functional Groups Via Click Chemistry in Highly Stable Metal-Organic Frameworks, J. Am. Chem. Soc. 2012, 134, 14690-14693. DOI: 10.1021/ja3063919.

(4) Ol'khovik, V. K.; Pap, A. A.; Vasilevskii, V. A.; Galinovskii, N. A.; Tereshko, S. N. Synthesis and Properties of Luminophores Derived from Fluorinated Biphenyls, Russ. J. Org. Chem. 2008, 44, 1172-1179. DOI: 10.1134/S1070428008080113.

(5) Halis, S.; Reimer, N.; Klinkebiel, A.; Lüning, U.; Stock, N. Four New Al-Based Microporous MetalOrganic Framework Compounds with Mil-53-Type Structure Containing Functionalized Extended Linker Molecules, Microporous Mesoporous Mater. 2015, 216, 13-19. DOI: doi.org/10.1016/j.micromeso.2015.01.030.

(6) Goswami, S.; Miller, C. E.; Logsdon, J. L.; Buru, C. T.; Wu, Y.-L.; Bowman, D. N.; Islamoglu, T.; Asiri, A. M.; Cramer, C. J.; Wasielewski, M. R.; Hupp, J. T.; Farha, O. K. Atomistic Approach toward Selective Photocatalytic Oxidation of a Mustard-Gas Simulant: A Case Study with Heavy-ChalcogenContaining Pcn-57 Analogues, ACS Appl. Mater. Interfaces 2017, 9, 19535-19540. DOI: 10.1021/acsami.7b07055.

(7) Schaate, A.; Roy, P.; Godt, A.; Lippke, J.; Waltz, F.; Wiebcke, M.; Behrens, P. Modulated Synthesis of Zr-Based Metal-Organic Frameworks: From Nano to Single Crystals, Chem. Eur. J 2011, 17, 66436651. DOI: 10.1002/chem.201003211.

(8) Rockland, L. B. Saturated Salt Solutions for Static Control of Relative Humidity between $5^{\circ}$ and $40^{\circ}$ C, Anal. Chem. 1960, 32, 1375-1376. DOI: 10.1021/ac60166a055.

(9) Carboni, M.; Lin, Z.; Abney, C. W.; Zhang, T.; Lin, W. A Metal-Organic Framework Containing Unusual Eight-Connected Zr-Oxo Secondary Building Units and Orthogonal Carboxylic Acids for Ultra-Sensitive Metal Detection, Chem. Eur. J 2014, 20, 14965-14970. DOI: 10.1002/chem.201405194.

(10) Shearer, G. C.; Chavan, S.; Bordiga, S.; Svelle, S.; Olsbye, U.; Lillerud, K. P. Defect Engineering: Tuning the Porosity and Composition of the Metal-Organic Framework UiO-66 Via Modulated Synthesis, Chem. Mater. 2016, 28, 3749-3761. DOI: 10.1021/acs.chemmater.6b00602.

(11) Klet, R. C.; Liu, Y.; Wang, T. C.; Hupp, J. T.; Farha, O. K. Evaluation of Brønsted Acidity and Proton Topology in Zr- and Hf-Based Metal-Organic Frameworks Using Potentiometric Acid-Base Titration, J. Mater. Chem. A 2016, 4, 1479-1485. DOI: 10.1039/C5TA07687K.

(12) Ko, N.; Hong, J.; Sung, S.; Cordova, K. E.; Park, H. J.; Yang, J. K.; Kim, J. A Significant Enhancement of Water Vapour Uptake at Low Pressure by Amine-Functionalization of UiO-67, Dalton Trans. 2015, 44, 2047-2051. DOI: 10.1039/C4DT02582B.

(13) Tan, C.; Han, X.; Li, Z.; Liu, Y.; Cui, Y. Controlled Exchange of Achiral Linkers with Chiral Linkers in ZrBased Uio-68 Metal-Organic Framework, J. Am. Chem. Soc. 2018, 140, 16229-16236. DOI: 10.1021/jacs.8b09606. 